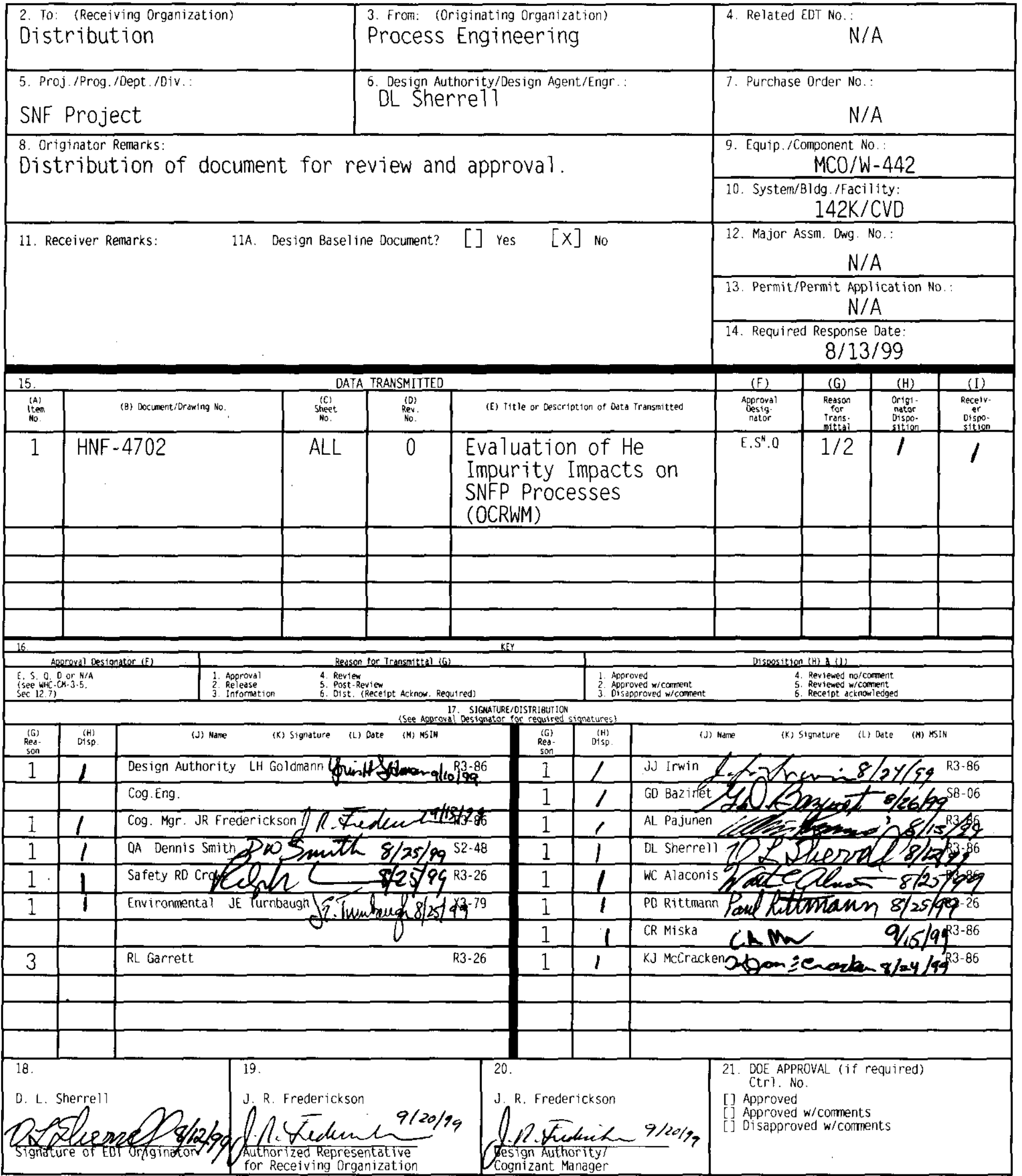


Evaluation of Helium Impurity Impacts on Spent Nuclear Fuel Project Processes (OCRWM)

\author{
D. L. Sherrell and A. L. Pajunen \\ NUMATEC Hanford Company, Richland, WA 99352 \\ U.S. Department of Energy Contract DE-AC06-96RL13200 \\ EDT/ECN : 627431 UC: 510 \\ Org Code: 81000 Charge Code: LB051 \\ $B \& R$ Code: EW04J110 Total Pages:5|
}

Key Words: Spent Nuclear Fuel (SNF) Project, K Basins, Multicanister Overpack(MCO), Cold Vacuum Drying (CVD) Facility, Helium Impurity Impacts, Helium Procurement specification

Abstract: This document identifies the types and quantities of impurities that may be present within helium that is introduced into multi-canister overpacks (MCO)s by various SNF Project facilities, including, but not limited to the cold Vacuum Drying (CVD) Facility (CVDF). It then evaluates possible impacts of worst case impurity inventories on MCO drying, transportation, and storage processes. Based on the evaluation results, this document: 1) concludes that the SNF Project helium procurement specification can be a factor-of-ten less restrictive than a typical vendor's standard offering $(99.96 \%$ pure versus the vendor's $99.997 \%$ pure standard offering); 2) concludes that the CVDF's current $99.5 \frac{9}{8}$ purity requirement is adequate to control the quality of the helium that is delivered to the MCO by the plant's helium distribution system; and 3) recommends specific impurity limits for both of the above cases.

TRADEMARK DISCLAIMER. Reference herein to any specific cormercial product. process. or service by trade name. trademark. manufacturer. or otherwise. does not necessarily constitute or imply its endorsement. recomendation, or favoring by the United States Governinent or any agency thereof or its contractors or subcontractors.

Printed in the United States of America. To obtain copies of this document. contact: Document Control Services. P.0. Box 950. Mailstop H6-08. Richland WA 99352. Phone (509) 372-2420: Fax (509) 376-4989.

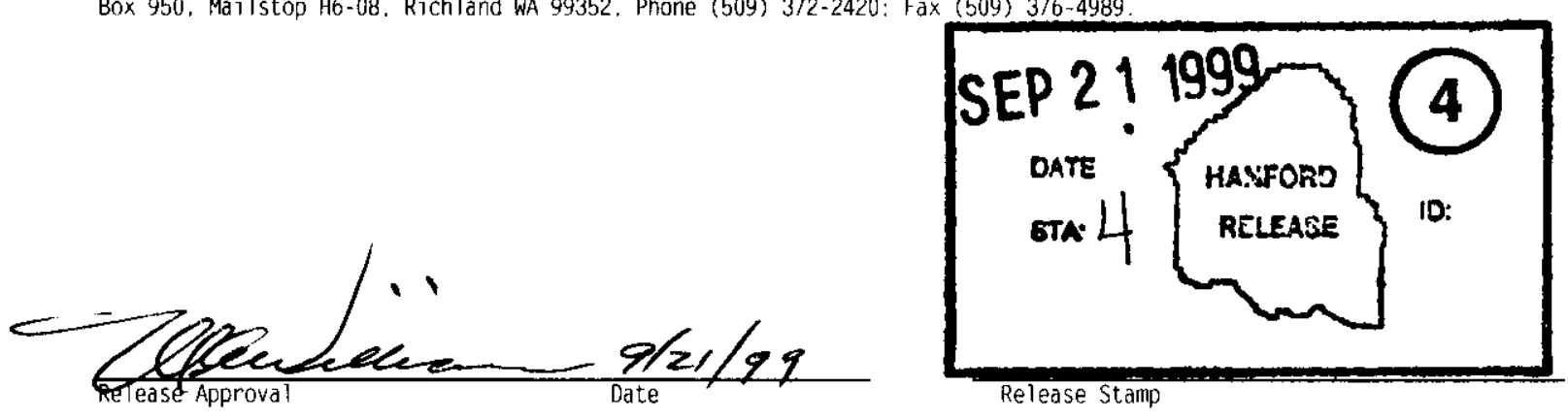

Approved for Public Release 


\section{Evaluation of Helium Impurity Impacts on Spent Nuclear Fuel Project Processes (OCRWM)}

TASK ORDER:

SUB-PROJECT:

PREPARED BY:
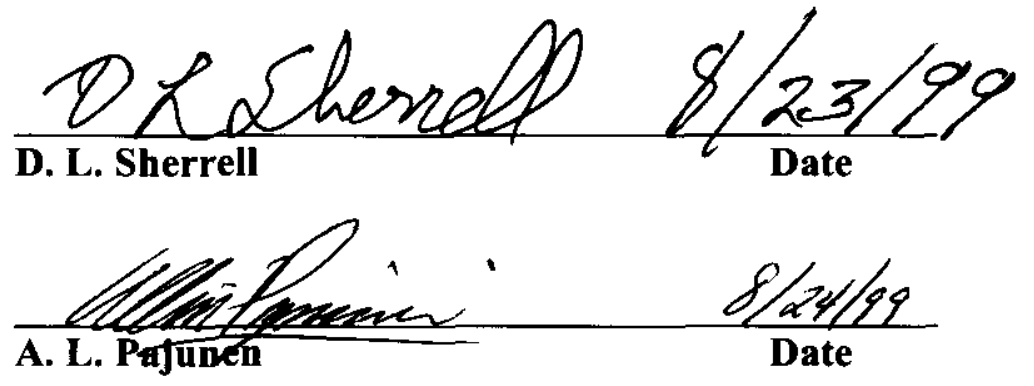

TECHNICAL CHECKER: Panf Rittimann 8-25-99 


\section{HNF-4702, Rev. 0 \\ EVALUATION OF HELIUM IMPURITY IMPACTS ON SPENT NUCLEAR FUEL PROJECT PROCESSES (OCRWM)}

TABLE OF CONTENTS

1.0 PURPOSE AND OBJECTIVE 1

2.0 SUMMARY OF FINAL RESULTS AND CONCLUSIONS .................................................2

2.1 SNF PROJECT HELIUM GAS PROCUREMENT SPECIFICATION ...............................2

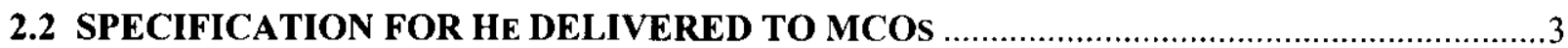

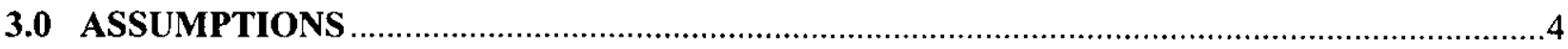

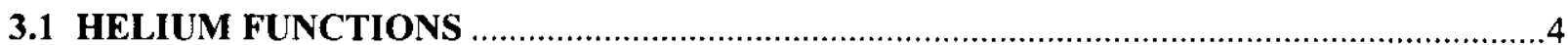

3.2 HELIUM SUPPLY SYSTEM

3.2.1 Impurity Levels in Vendor Supplied Helium .......................................................

3.2.2 Impurity Levels in Helium Delivered to MCOs ...............................................................

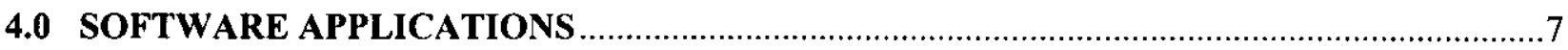

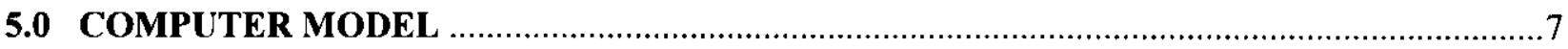

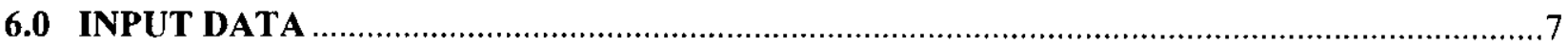

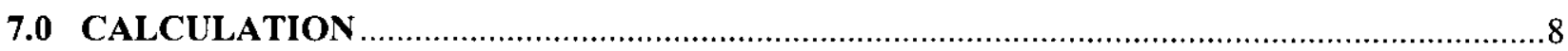

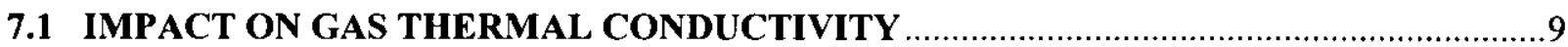

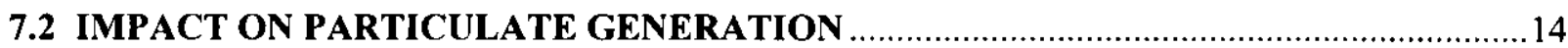

7.2.1 Evaluation of Impurities Listed for the Air Ingress Case of Table 3-2 ........................... 14

7.2.2 Evaluation of Impurities Listed for the Water Ingress Case of Table 3-2 .....................15

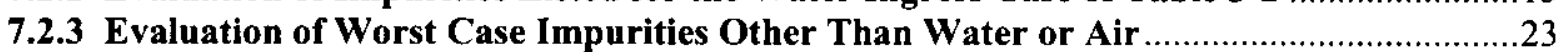

7.3 IMPACT ON PEAK HYDROGEN GENERATION RATES …..................................2.

7.3.1 Evaluation of Impurities Listed for the Air Ingress Case of Table 3-2 .........................2.25

7.3.2 Evaluation of Impurities Listed for the Water Ingress Case of Table 3-2 ….................25

7.3.3 Evaluation of Worst Case Impurities Other Than Water or Air ...............................26

7.4 IMPACT ON REACTION HEAT GENERATION RATES …......................................2

7.4.1 Evaluation of Impurities Listed for the Air Ingress Case of Table 3-2 .........................27

7.4.2 Evaluation of Impurities Listed for the Water Ingress Case of Table 3-2 ..................27

7.4.3 Evaluation of Worst Case Impurities Other Than Water or Air ...................................30

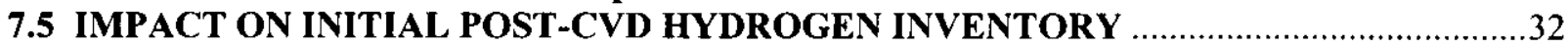

7.6 IMPACT ON INITIAL POST CVD PROCESSING HELIUM INVENTORY .....................32

7.7 IMPACT ON GAS COMPOSITION DURING INTERIM STORAGE …..........................33

7.7.1 Evaluation of Impurities Listed for the Water Ingress Case of Table 3-2 …...............33

7.7.2 Evaluation of Impurities Listed for the Air Ingress Case of Table 3-2 ..........................34

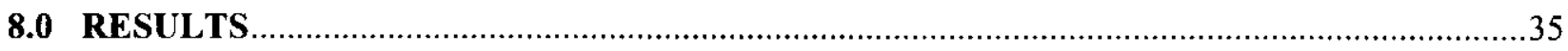

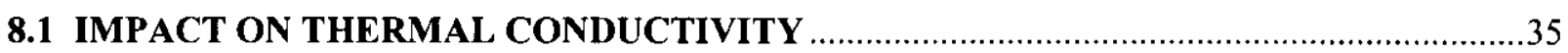

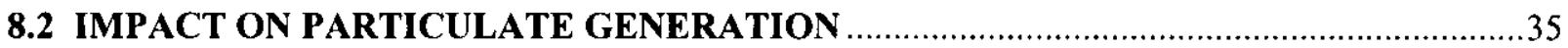

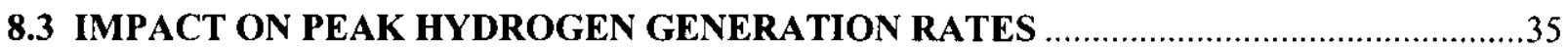

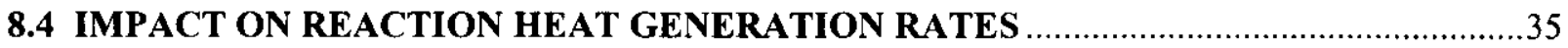

8.5 IMPACT ON INITIAL POST-CVD PROCESSING HYDROGEN INVENTORY …............35

8.6 IMPACT ON INITIAL POST-CVD PROCESSING HELIUM INVENTORY ......................36

8.7 IMPACT ON GAS COMPOSITION DURING INTERIM STORAGE …............................36 
9.1 SNF PROJECT HELIUM GAS PROCUREMENT SPECIFICATION 37

9.2 HELIUM DELIVERED TO MCOS BY PLANT PIPING SYSTEMS

APPENDIX A: VENDOR SUPPLIED COMPOSITION INFORMATION (OXARC, INC). 41

APPENDIX B: INDEPENDENT REVIEW 43

FIGURE LIST

Figure 3-1. Schematic of Gas Impurity System Evaluation 4

Figure 7-1. Thermal Conductivities of Vendor Supplied Helium Gas Constituents ............ 9

Figure 7-2. Thermal Conductivity of Worst Case Helium Distributed to MCO

\section{TABLE LIST}

Table 2-1. Recommended SNF Project Helium Gas Procurement Specification 2

Table 2-2. Recommended Specification for He Delivered to MCOs ................................ 3

Table 3-1. Assumed Vendor Supplied Helium Gas Composition................................... 5

Table 3-2. Assumed Helium Gas Compositions Supplied to the MCO............................ 6

Table 7-1. Reference Used for Calculation of Gas Thermal Conductivities .................... 10

Table 7-2. Calculated Gas Thermal Conductivities $(\mu \mathrm{cal} / \mathbf{s}-\mathbf{c m}-\mathrm{K})$................................. 11

Table 7-3. Calculated Gas Thermal Conductivities after Conversion to $W / \mathbf{m}-K \ldots \ldots \ldots \ldots . . . . .11$

Table 7-4. Calculated Thermal Conductivities for Worst Case Supply Gas..................... 12

Table 7-5. Calculation of Incremental Particulate from Table 3-2 Water Case ................ 15

Table 7-6. Calculation of Incremental Reaction Heat from Table 3-2 Water Case ........... 28

Table 9-1. Recommended SNF Project Helium Gas Procurement Specification ............... 37

Table 9-2. Recommended Specification for He Delivered to MCOs ............................ 38 


\subsection{PURPOSE AND OBJECTIVE}

The purpose of this evaluation is to identify the types and quantities of impurities that may be present within helium that is introduced into a multi-canister overpack (MCO) by the Cold Vacuum Drying (CVD) process, access their impacts on the overall Spent Nuclear Fuel (SNF) storage process, and thereby establish: 1) the purity specification for helium as it is delivered to the Cold Vacuum Drying facility (CVDF) by the vendor; and 2) confirm acceptability of the CVDF's $99.5 \%$ purity specification (Irwin 1999a) for helium as it is delivered to MCOs by the facility. Item 1, the evaluated impurity limit for helium as it is supplied by the vendor, will form the basis for helium essential material specifications (i.e., the helium gas procurement specification) for all of the sub-projects under the SNF Project.

In general, the SNF Project's existing system analyses assume that pure helium is introduced into the $\mathrm{MCO}$ when called for by the process. However, even if the vendor were to supply the facility with an "ultra-pure" grade of helium, it would not be practical for the facility to maintain that level of purity because of the potential for inadvertent introduction of air and/or moisture into the helium piping during supply change-overs, $\mathrm{MCO}$ connection operations, or system maintenance activities. Consequently, it is necessary to evaluate impacts from higher impurity levels within the helium that is actually introduced into MCOs. 


\subsection{SUMMARY OF FINAL RESULTS AND CONCLUSIONS}

Based on the calculations and discussions in section 7.0, no SNF Project process or system analysis would be impacted if: a) the helium procurement specification for the SNF Project were to allow more than ten times the total impurity limit of a typical vendor's standard offering, with individual impurity limits that exceed most of the vendor's individual limits by a factor-of-ten (the $2 \mathrm{ppm}$ total hydrocarbon limit is the exception); and b) the facility helium distribution equipment and operations were allowed to further contaminate the helium with air and/or moisture, provided that the helium is maintained at least $99.5 \%$ pure and that hydrocarbons (as methane) are maintained at or below $10 \mathrm{ppm}$.

\subsection{SNF PROJECT HELIUM GAS PROCUREMENT SPECIFICATION}

Table 2-1 lists the recommended helium purity requirement ( $\geq 99.96 \%$ ), along with the individual impurity limits for the SNF Project helium procurement specification. Note that, for the purposes of this specification, a mole-to-mole basis is considered equivalent to a volume-tovolume basis. Also note that the $\geq 99.96 \%$ minimum purity requirement (i.e., 400 ppm maximum total impurities) would be violated if all of the listed impurities were to be present at their maximum individual limits (i.e., 462 ppm total impurities). This is typical of most, if not all, commercial gas purity specifications. See section 9.1 for a discussion of the recommended specification, which is reproduced there as Table 9-1.

Table 2-1. Recommended SNF Project Helium Gas Procurement Specification

\begin{tabular}{|l|c|}
\hline \multicolumn{2}{|c|}{ ComELIUM GAS PROCUREMENT SPECIFICATION } \\
\hline $\mathrm{He}$ & Requirement (mole-to-mole basis) \\
\hline $\mathrm{H}_{2} \mathrm{O}$ & $\leq 99.96 \%$ \\
\hline Total Hydrocarbon (as $\mathrm{CH}_{4}$ ) & $\leq 50 \mathrm{ppm}$ \\
\hline $\mathrm{O}_{2}+\mathrm{Ar}$ & $\leq 3 \mathrm{ppm}$ \\
\hline $\mathrm{N}_{2}$ & $\leq 60 \mathrm{ppm}$ \\
\hline $\mathrm{Ne}$ & $\leq 300 \mathrm{ppm}$ \\
\hline $\mathrm{H}_{2}$ & $\leq 10 \mathrm{ppm}$ \\
\hline $\mathrm{CO}_{2}$ & $\leq 10 \mathrm{ppm}$ \\
\hline
\end{tabular}




\subsection{SPECIFICATION FOR HE DELIVERED TO MCOs}

Table 2-2 provides the recommended overall purity requirement $(\geq 99.5 \%)$ and individual impurity limits for the helium that is actually introduced into MCOs by the plant's gas distribution piping. Note that any individual impurity may be present in concentrations at or below its listed limit, provided that the helium is maintained at least $99.5 \%$ pure, which is to say that the sum of the individual impurities actually present may not exceed $5000 \mathrm{ppm}$ for any given case, even though the sum of the individual limits listed in Table 2-2 totals almost twice that amount. See section 9.2 for a discussion of the recommended specification, which is reproduced there as Table 9-2. Note that this specification is not limited to the CVDF and may be applied to all SNF Project facilities that introduce helium into the $\mathrm{MCO}$ or the $\mathrm{MCO} / \mathrm{Cask}$ assembly.

Table 2-2. Recommended Specification for He Delivered to MCOs

\begin{tabular}{|l|c|}
\hline \multicolumn{2}{|c|}{$\mathrm{He}$ DELIVERED to MCOs via PLANT PIPING SYSTEMS } \\
\hline \multicolumn{1}{|c|}{ Component } & Requirement \\
\hline $\mathrm{He}$ & $\geq 99.5 \%$ \\
\hline $\mathrm{H}_{2} \mathrm{O}$ & $\leq 4580 \mathrm{ppm}$ \\
\hline Total Hydrocarbon (as $\left.\mathrm{CH}_{4}\right)$ & $\leq 10 \mathrm{ppm}$ \\
\hline $\mathrm{O}_{2}+\mathrm{Ar}$ & $\leq 1020 \mathrm{ppm}$ \\
\hline $\mathrm{N}_{2}$ & $\leq 3600 \mathrm{ppm}$ \\
\hline $\mathrm{Ne}$ & $\leq 300 \mathrm{ppm}$ \\
\hline $\mathrm{H}_{2}$ & $\leq 10 \mathrm{ppm}$ \\
\hline $\mathrm{CO}_{2}$ & $\leq 11 \mathrm{ppm}$ \\
\hline
\end{tabular}




\subsection{ASSUMPTIONS}

\subsection{HELIUM FUNCTIONS}

This evaluation is based on the project's use of helium to provide the following functions at one point or another in the overall fuel removal and storage process: 1) prevent air from contacting fuel assemblies by providing an inert gas cover over the fuel assemblies within the MCOs; 2 ) in order to prevent combustion of hydrogen within MCOs, preclude air ingress to MCOs by maintaining them at a positive gage pressure during those CVD operations that do not require MCOs to be under vacuum, and during subsequent transport to, and storage at, the Canister Storage Building (CSB); 3) serve as an inert cover and/or purge gas to enhance heat transfer within MCOs during some CVD operations (e.g., the "thermal reset" operation), and during all transport and storage operations; and 4) serve as an inert purge gas to displace any air within process lines, tanks, etc., prior to introduction of hydrogen contaminated cover gas from MCOs.

\subsection{HELIUM SUPPLY SYSTEM}

Figure 3-1 describes the system assumed to evaluate helium impurity impacts on MCO drying and storage processes. This assumed "system" actually represents two different facility systems, the General Service Helium System (Sys. 13-1) and the Safety Class Helium Purge System (Sys. 13-2). The general service system receives helium from the vendor within vendor supplied "Tube Trailers," i.e., within long, tractor-trailer mounted, horizontal gas cylinders ("tubes") that are manifolded together to provide a single connection point for the facility's distribution system. The safety class system, on the other hand, receives helium via standard size gas cylinders that must be changed out individually. If the safety class system's gas cylinders were to require frequent change-outs, they could represent a greater potential for contamination by air than that presented by the tube trailers. However, because the safety class gas cylinders will seldom require replacement, the general service system (which is more extensive, and which may require several tube trailer change-outs per month) probably has the greatest contamination potential. Consequently, Figure 3-1 is based on the General Service Helium System (Sys. 13-1).

Figure 3-1. Schematic of Gas Impurity System Evaluation

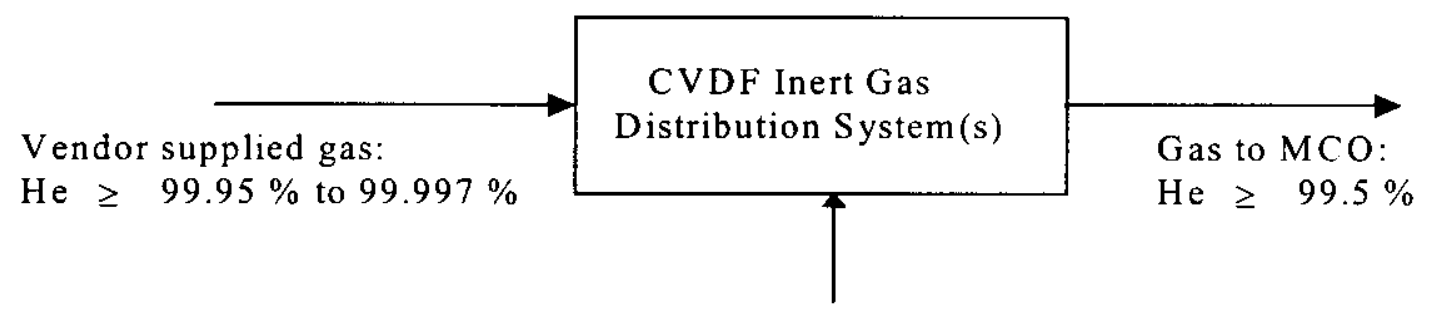

Air and/or water ingress

(plus trace hydrocarbons from piping) 


\subsubsection{Impurity Levels in Vendor Supplied Helium}

The center column of Table 3-1 summarizes maximum impurity levels for a typical vendor supplied gas, as listed on the data sheet attached as Appendix A. That vendor's standard industrial grade of helium (listed as their "standard offering" by Note 2 of the attachment) is required to contain less than $30 \mathrm{ppm}$ total impurities (i.e., it is $99.997 \%$ pure), even though the total would approach $50 \mathrm{ppm}$ if all of the listed impurities were to be concurrently present at their maximum allowed concentrations within a given lot of gas. To provide for conservatism in this evaluation and future flexibility in the specification of essential materials, the individual maximum impurity levels of the standard industrial gas were increased by an order of magnitude, with the exception of the total hydrocarbon limit, which was only doubled. The right hand column of Table 3-1 lists the resulting worst case gas composition that will form the basis for helium essential material specifications to the vendor, prior to allowing for contamination by the facility's gas distribution system. This evaluated basis was used as a starting point for defining the maximum impact of impurities. Note that the maximum total impurity limit for this column ( $462 \mathrm{ppm}$, or $99.9538 \%$ purity) is based on adding up the individual limits to obtain the $462 \mathrm{ppm}$ value for maximum total impurities, as opposed to limiting the total to ten times the vendor's 30 ppm value (i.e., $300 \mathrm{ppm}$, or $99.97 \%$ purity). Also note that the gas composition delivered to MCOs was taken as the worst case component at the maximum evaluated total impurity limit for some evaluations in order to simplify calculations.

Table 3-1. Assumed Vendor Supplied Helium Gas Composition

\begin{tabular}{|l|c|c|}
\hline \multicolumn{1}{|c|}{ Component } & Expected Impurity Basis & Evaluated Impurity Basis \\
\hline $\mathrm{He}$ & $\geq 99.997 \%$ & $\geq 99.9538 \%$ \\
\hline & $\leq 5 \mathrm{ppm}$ & $\leq 50 \mathrm{ppm}$ \\
\hline $\mathrm{H}_{2} \mathrm{O}$ & $\leq 1 \mathrm{ppm}$ & $\leq 2 \mathrm{ppm}$ (see note 1$)$ \\
\hline Total Hydrocarbon $\left(\right.$ as $\left.\mathrm{CH}_{4}\right)$ & $\leq 3 \mathrm{ppm}$ & $\leq 30 \mathrm{ppm}$ \\
\hline $\mathrm{O}_{2}+\mathrm{Ar}$ & $\leq 6 \mathrm{ppm}$ & $\leq 60 \mathrm{ppm}$ \\
\hline $\mathrm{N}_{2}$ & $\leq 30 \mathrm{ppm}$ & $\leq 300 \mathrm{ppm}$ \\
\hline $\mathrm{Ne}$ & $\leq 1 \mathrm{ppm}$ & $\leq 10 \mathrm{ppm}$ \\
\hline $\mathrm{H}_{2}$ & $\leq 1 \mathrm{ppm}$ & $\leq 10 \mathrm{ppm}$ \\
\hline $\mathrm{CO}_{2}$ & & $\leq$ \\
\hline
\end{tabular}

1. The hydrocarbon impurity limit for vendor supplied helium is held to within a factor-of-two (as opposed to ten) of a typical vendor's "standard offering" in order to allow for additional hydrocarbon contamination by SNF Project systems and/or operations.

\subsubsection{Impurity Levels in Helium Delivered to MCOs}

Table 3-2 presents two possible worst case gas compositions for helium as it is actually delivered to the MCO, based on further contamination (by facility systems/operations) of the assumed worst case vendor supplied helium up to the $5000 \mathrm{ppm}$ maximum total impurity limit $(\geq 99.5 \%$ pure) specified for design of the facility's helium distribution systems (Irwin 1999a). The impurity levels listed by the center column of Table 3-2 are based on contamination of the worst case helium from Table 3-1 by inadvertent introduction of bone-dry air, whereas those in the right hand column are based on contamination by pure water or water vapor. Because the most likely contamination source is moist air, the two extremes presented in Table 3-2 (all air or all water) should be adequate for this evaluation. Both cases allow for $8 \mathrm{ppm}$ of additional $\mathrm{CH}_{4}$. 
HNF-4702, Rev. 0

Table 3-2. Assumed Helium Gas Compositions Supplied to the MCO

\begin{tabular}{|l|c|c|}
\hline \multicolumn{1}{|c|}{ Component } & Air Ingress & Water Vapor Ingress \\
\hline $\mathrm{He}$ & $99.5 \%$ & $99.5 \%$ \\
\hline & $50 \mathrm{ppm}$ & $4,580 \mathrm{ppm}$ \\
\hline $\mathrm{H}_{2} \mathrm{O}$ & $10 \mathrm{ppm}$ & $10 \mathrm{ppm}$ \\
\hline Total Hydrocarbon (as $\mathrm{CH}_{4}$ ) & $1,020 \mathrm{ppm}$ & $30 \mathrm{ppm}$ \\
\hline $\mathrm{O}_{2}+\mathrm{Ar}$ & $3,600 \mathrm{ppm}$ & $60 \mathrm{ppm}$ \\
\hline $\mathrm{N}_{2}$ & $300 \mathrm{ppm}$ & $300 \mathrm{ppm}$ \\
\hline $\mathrm{Ne}$ & $10 \mathrm{ppm}$ & $10 \mathrm{ppm}$ \\
\hline $\mathrm{H}_{2}$ & $11 \mathrm{ppm}$ & $10 \mathrm{ppm}$ \\
\hline $\mathrm{CO}_{2}$ & & \\
\hline
\end{tabular}

1. Assumes "Evaluated Impurity Basis" from Table 3-1 as the starting point for gas composition entering the helium gas distribution system, plus hydrocarbon contamination (an additional $8 \mathrm{ppm}$ ) from the distribution piping, to which is added either air ingress or water vapor contamination.

Sample calculation of gas composition listed in Table 3-2 Basis: 100 mol supply gas

\begin{tabular}{|l|c|c|c|c|}
\hline \multirow{2}{*}{ Component } & Supply Gas, & Air $+\mathrm{CH}_{4}$ & \multicolumn{2}{c|}{ Gas to MCO } \\
\cline { 4 - 5 } & mol & Ingress, mol & mol & composition \\
\hline $\mathrm{He}$ & 99.9538 & - & 99.9538 & $99.5 \%$ \\
\hline $\mathrm{H}_{2} \mathrm{O}$ & 0.0050 & - & 0.0050 & $50 \mathrm{ppm}$ \\
\hline $\mathrm{CH}_{4}$ (see note 1) & 0.0002 & 0.0008 & 0.0010 & $10 \mathrm{ppm}$ \\
\hline $\mathrm{O}_{2}+\mathrm{Ar}$ & 0.0030 & 0.0996 & 0.1026 & $1,020 \mathrm{ppm}$ \\
\hline $\mathrm{N}_{2}$ & 0.0060 & 0.3556 & 0.3616 & $3,600 \mathrm{ppm}$ \\
\hline $\mathrm{Ne}$ & 0.0300 & - & 0.0300 & $300 \mathrm{ppm}$ \\
\hline $\mathrm{H}_{2}$ & 0.0010 & - & 0.0010 & $10 \mathrm{ppm}$ \\
\hline $\mathrm{CO}_{2}$ & 0.0010 & 0.0001 & 0.0011 & $11 \mathrm{ppm}$ \\
\hline TOTAL mol & 100.0000 & 0.4561 & 100.4561 & \\
\hline
\end{tabular}

1. The 0.0008 moles of $\mathrm{CH}_{4}$ reflect $8 \mathrm{ppm}$ of additional hydrocarbon contamination by plant systems/operations, resulting in a $0.001 \mathrm{~mol}$ total hydrocarbon inventory at the final $10 \mathrm{ppm}$ limit ( $2 \mathrm{ppm}$ from vendor $+8 \mathrm{ppm}$ from plant).

Per the "Evaluated Impurity Basis" column of Table 3-1, the 100 moles of supply gas would contain no more than 99.9538 moles of helium. This is reflected in the "Supply Gas" column of the above table. And, based on the $99.5 \%$ purity specification established by the CVDF system design requirements document (Irwin 1999a), the mole fraction of helium within the gas actually introduced into the MCO may be as low as 0.995 . For 100 moles of supply gas (prior to contamination by the CVDF distribution system): $\mathrm{n}_{\mathrm{T}}=100 \mathrm{~mol}+\mathrm{n}_{\text {Air }}+\mathrm{n}_{\text {Pipe }}$, where

$\mathrm{n}_{\mathrm{T}}=$ the total moles of gas actually delivered to MCOs per $100 \mathrm{~mol}$ of supply gas

$\mathrm{n}_{\text {Pipe }}=0.0008 \mathrm{~mol}$ (corresponds to $\sim 8 \mathrm{ppm}$ ) of hydrocarbon contamination from piping internals

$\mathrm{n}_{\text {Air }}+\mathrm{n}_{\text {Pipe }}=$ the amount (moles) of air and hydrocarbons required to reduce the concentration of helium in 100 moles of supply gas from the evaluated impurity basis of Table $3-1(99.9538 \%$ ) down to the $99.5 \%$ purity basis of Table $3-2$, then

$$
0.995=(99.9538 \mathrm{~mol}) / \mathrm{n}_{\mathrm{T}} \mathrm{mol} \text {, and } \mathrm{n}_{\mathrm{T}}=(99.9538) /(0.995)=\underline{100.4561 \text { moles}} .
$$

The maximum allowed air ingress during gas distribution is, therefore, $0.4561 \mathrm{~mol}-0.0008 \mathrm{~mol}$ $=\mathbf{0 . 4 5 5 3} \mathbf{~ m o l}$ per 100 moles of vendor supplied gas that enters the plant's distribution system. 
Based on atmospheric concentrations from page 164 of [Lange's], the 0.4553 moles of air include the following constituents/molar quantities (listed under "Air Ingress" in the above table):

$$
\begin{aligned}
& \mathrm{N}_{2}--0.7810(0.4553)=0.3556 \mathrm{~mol} ; \\
& \mathrm{O}_{2}-0.2095(0.4553)=0.0954 \mathrm{~mol} ; \\
& \mathrm{Ar}-0.0093(0.4553)=0.0042 \mathrm{~mol} ; \\
& \mathrm{CO}_{2}-0.0003(0.4553)=0.0001 \mathrm{~mol}
\end{aligned}
$$

The impurity quantities listed under "Supply Gas" are added to the corresponding quantities listed under "Air Ingress" to obtain the values listed in the left column under "Gas to MCO". Finally, those values are each divided by the total quantity of gas $(100.4561 \mathrm{~mol})$ to obtain the compositions listed in the right column:

$$
\begin{aligned}
& \mathrm{He}=99.9538 \mathrm{~mol} / 100.4561 \mathrm{~mol}=0.9950=99.5 \% \\
& \mathrm{H}_{2} \mathrm{O}=10^{6} \times 0.005 \mathrm{~mol} / 100.4561 \mathrm{~mol}=49.8 \mathrm{ppm}=\mathbf{5 0} \mathbf{p p m} \\
& \mathrm{CH}_{4}=10^{6} \times 0.001 \mathrm{~mol} / 100.4561 \mathrm{~mol}=9.96 \mathrm{ppm}=10 \mathbf{p p m} \\
& \mathrm{O}_{2}+\mathrm{Ar}=10^{6}(0.003 \mathrm{~mol}+0.0954 \mathrm{~mol}+0.0042) / 100.4561 \mathrm{~mol}=1021 \mathrm{ppm}, \mathbf{U S E} 1020 \mathbf{p p m} \\
& \mathrm{N}_{2}=10^{6}(0.006 \mathrm{~mol}+0.3556 \mathrm{~mol}) / 100.4561 \mathrm{~mol}=3599.6 \mathrm{ppm}=3600 \mathbf{p p m} \\
& \mathrm{Ne}=10^{6} \times 0.030 / 100.4561 \mathrm{~mol}=298.6 \mathrm{ppm}, \text { USE } 300 \mathbf{p p m} \\
& \mathrm{H}_{2}=10^{6} \times 0.001 / 100.4561 \mathrm{~mol}=9.96 \mathrm{ppm}=\mathbf{1 0} \mathbf{p p m} \\
& \mathrm{CO}_{2}=10^{6}(0.001 \mathrm{~mol}+0.0001 \mathrm{~mol}) / 100.4561 \mathrm{~mol}=10.95 \mathrm{ppm}=11 \mathbf{p p m}
\end{aligned}
$$

\subsection{SOFTWARE APPLICATIONS}

This calculation is basically a hand calculation. The spreadsheet software application, Microsoftß Excel 97 SR-1, was used to replicate calculations and graph results. Microsoft Excel 97 SR-1 is a product of the Microsoft Corporation.

\subsection{COMPUTER MODEL}

No computer models were used.

\subsection{INPUT DATA}

All input data is referenced as it is used in the calculations. 


\subsection{CAlculation}

The cask/MCO assembly is backfilled with helium at the basins prior to its transfer to the CVDF. The helium backfill is intended to eliminate the potential for forming combustible gas mixtures within the cask/MCO (it reduces the oxygen concentration in void regions). At this point in the process, the fuel assemblics within the MCO are covered by water. Upon receipt at the CVDF, helium is used to control the potential for combustible gas mixtures during cask lid removal. Helium is also used for a variety of operations during the drying process at the CVDF. The CVDF uses are listed below.

- Purging hydrogen from the MCO void space prior to draining (fuel covered with water).

- Pressurizing the MCO to facilitate the draining process.

- Purging the $\mathrm{MCO}$ during the drying process at vacuum conditions to control the potential for forming combustible gas mixtures.

- Thermal Reset -- an atmospheric pressure helium purge through the MCO between evacuated phases of the drying process that is used to equilibrate fuel temperature gradients that may develop under vacuum conditions.

- Re-pressurization of the MCO (from the safety class helium system) during any off-normal events that may occur.

- Purging process water conditioning system receiver tanks to control the potential for forming combustible gas mixtures.

- Backfilling the MCO after drying to provide a tracer gas (i.e., the helium) for leak-testing seals, and to maintain the MCO pressurized throughout the interim storage time period (minimizes potential for oxygen ingress and dilutes oxygen that is formed via radiolysis).

Helium may also be used at the canister storage building to backfill MCOs that are sampled as part of a monitoring program. 


\subsection{IMPACT ON GAS THERMAL CONDUCTIVITY}

Based on the following discussions and tabulated calculation results, the thermal conductivity of the worst case supply gas allowed by [Irwin 1999a] would be within $1 \%$ of the thermal conductivity listed for pure helium under all anticipated normal and off-normal MCO process conditions. Considering the uncertainties inherent in a typical thermal analysis, it is reasonable to conclude that the small conductivity difference between pure helium and the worst case supply gas composition would have no impact on the validity of any thermal calculations that have been performed, or have yet to be performed, to support the SNF Project.

The worst case conductivity is calculated by first identifying the worst case constituent that could be present in the gas supplied to an MCO for the operating conditions of interest to the end users and then assuming that the entire $0.5 \mathrm{~mol} \%$ impurity allowance of [Irwin 1999a] is composed of that worst case constituent.

Based on the conductivity values listed in Table 7-3 and plotted in Figure 7-1, the conductivity of carbon dioxide is slightly lower than that of argon until the system temperature reaches $40^{\circ} \mathrm{C}$, after which argon is plainly the worst case constituent. In view of the fact that MCO payload temperatures are not an issue below $40^{\circ} \mathrm{C}$, argon has been selected as the worst case supply gas constituent for the purposes of thermal evaluations. Based on the calculated values listed in Table 7-4, Figure 7-2 provides thermal conductivity versus temperature plots for pure argon, pure helium, and the worst case gas mixture (99.5 mol\% He, $0.5 \mathrm{~mol} \% \mathrm{Ar})$, along with a plot of the thermal conductivity ratio between the worst case gas mixture and pure helium.

Figure 7-1. Thermal Conductivities of Vendor Supplied Helium Gas Constituents (Based on Conductivities Listed in Table 7-3)

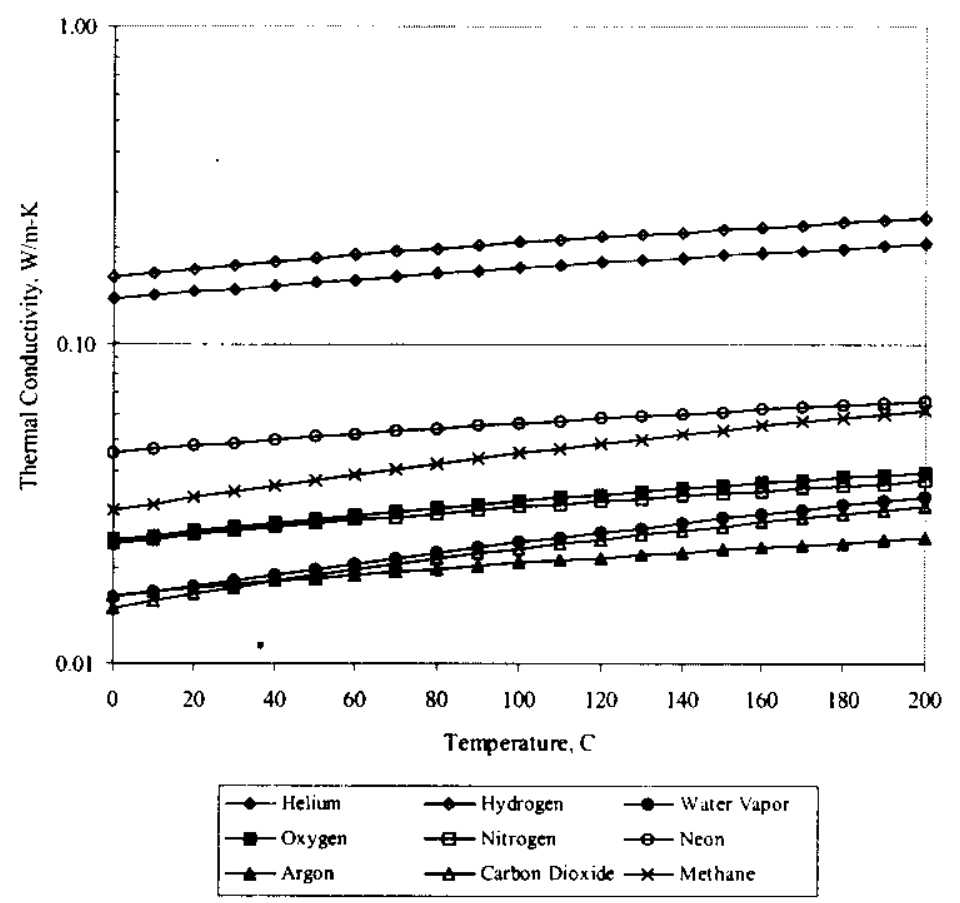


Figure 7-2. Thermal Conductivity of Worst Case Helium Distributed to MCO (Based on Values Listed in Table 7-4)

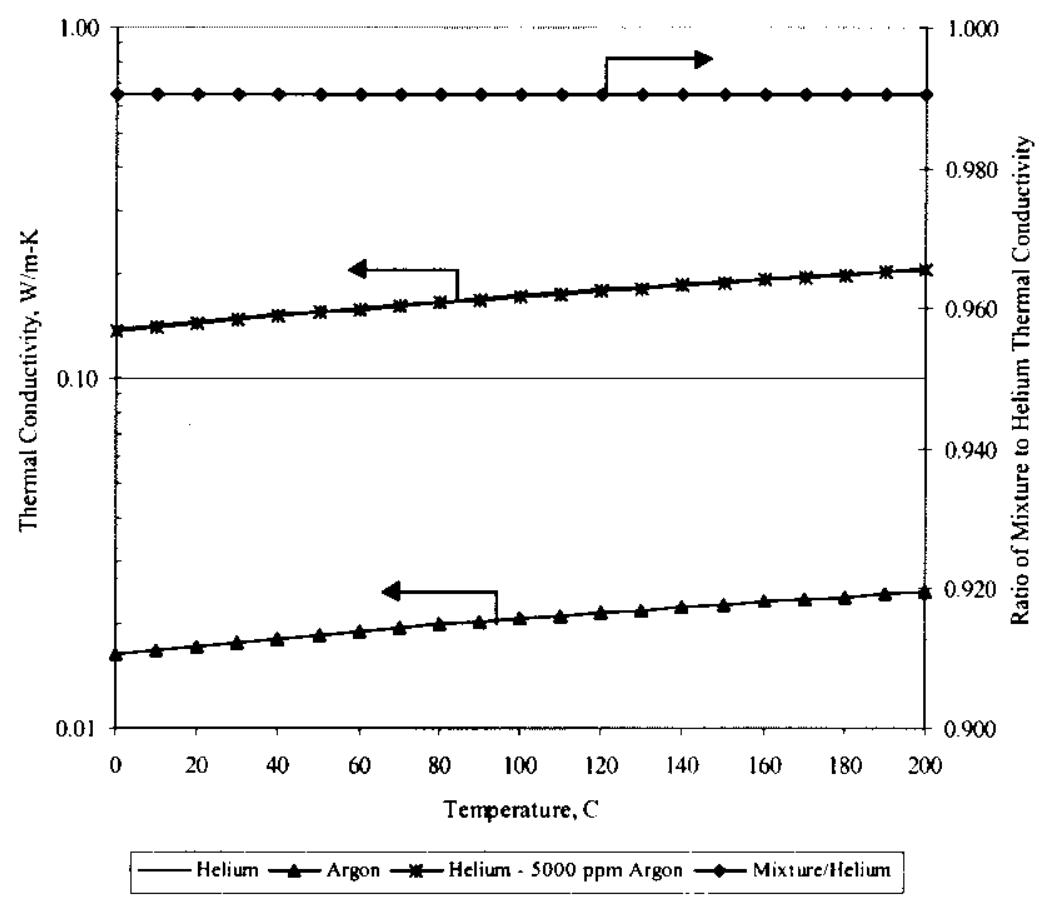

Table 7-1. Reference Used for Calculation of Gas Thermal Conductivities

Comparison of thermal conductivity of gases

from CL Yaws, Physical Properties - A guide to the physical, thermodynamic and transport property data of industrially important chemical compounds, McGraw-Hill Publishing Co, New York, New York, 1977.

From pgs. $208 \& 209$, correlation of data at $1 \mathrm{~atm}$ in the form, $\mathrm{k}=\mathrm{A}+\mathrm{BT}+\mathrm{CT}^{\wedge} 2+\mathrm{DT}^{\wedge} 3$

where $\mathrm{k}$ in ucal/s-cm-K and $\mathrm{T}$ in $\mathrm{K}$--- all values are listed exactly as shown in [Yaws 1977].

\begin{tabular}{|c|c|c|c|c|c|c|c|}
\hline & & & & & Value at $25 \mathrm{C}$ \\
\hline $\mathrm{Gas}$ & $\mathrm{A}$ & $\mathrm{B}$ & $\mathrm{C}$ & $\mathrm{D}$ & apply range, $\mathrm{C}$ & $\mu \mathrm{cal} / \mathrm{s}-\mathrm{cm}-\mathrm{K}$ \\
\hline $\mathrm{H}_{2} \mathrm{O}$ & 17.53 & $-2.420 \mathrm{E}-02$ & $4.300 \mathrm{E}-04$ & $-2.173 \mathrm{E}-07$ & 0 to 800 & 42.8 \\
\hline $\mathrm{H}_{2}$ & 19.34 & $1.597 \mathrm{E}+00$ & $-9.930 \mathrm{E}-04$ & $3.729 \mathrm{E}-07$ & -160 to 1200 & 417.22 \\
\hline $\mathrm{N}_{2}$ & 0.9359 & $2.344 \mathrm{E}-01$ & $-1.210 \mathrm{E}-04$ & $3.591 \mathrm{E}-08$ & -160 to 1200 & 61.02 \\
\hline $\mathrm{He}$ & 88.89 & $9.304 \mathrm{E}-01$ & $-1.790 \mathrm{E}-04$ & $3.090 \mathrm{E}-08$ & -160 to 800 & 31.20 \\
\hline $\mathrm{Ar}$ & 6.48 & $1.323 \mathrm{E}-01$ & $-5.200 \mathrm{E}-05$ & $1.320 \mathrm{E}-08$ & -160 to 1200 & 41.65 \\
\hline $\mathrm{CH}_{4}$ & -4.463 & $2.084 \mathrm{E}-01$ & $2.815 \mathrm{E}-04$ & $-8.631 \mathrm{E}-08$ & 0 to 1000 & 80.4 \\
\hline $\mathrm{O}_{2}$ & -0.7816 & $2.380 \mathrm{E}-01$ & $-8.939 \mathrm{E}-05$ & $2.324 \mathrm{E}-08$ & -160 to 1200 & 6 \\
\hline $\mathrm{Ne}$ & 21.75 & $3.681 \mathrm{E}-01$ & $-2.005 \mathrm{E}-04$ & $6.042 \mathrm{E}-08$ & -160 to 1200 & 62.8 \\
\hline $\mathrm{CO}_{2}$ & -17.23 & $1.914 \mathrm{E}-01$ & $1.308 \mathrm{E}-05$ & $-2.514 \mathrm{E}-08$ & -90 to 1400 & 115.3 \\
\hline
\end{tabular}

\section{Sample calculation of gas (argon) thermal conductivity at $30^{\circ} \mathrm{C}$}

Gas: Argon --- $\mathrm{T}=30^{\circ} \mathrm{C}=303 \mathrm{~K}--\mathrm{k}(\mu \mathrm{cal} / \mathrm{s}-\mathrm{cm}-\mathrm{K})=\mathrm{A}+\mathrm{BT}+\mathrm{CT}^{2}+\mathrm{DT}^{3}$

$$
\mathrm{k}=6.48+(303) 1.323 \times 10^{-1}-(303)^{2} 5.200 \times 10^{-5}+(303)^{3} 1.320 \times 10^{-8}=
$$

$6.48+40.087-4.774+0.367=42.16 \mu \mathrm{cal} / \mathrm{s}-\mathbf{c m}-\mathrm{K}$ (see listing in Table $7-2)$ 
HNF-4702, Rev. 0

Table 7-2. Calculated Gas Thermal Conductivities ( $\mu \mathrm{cal} / \mathrm{s}-\mathrm{cm}-\mathrm{K}$ )

\begin{tabular}{|c|c|c|c|c|c|c|c|c|c|c|}
\hline \multicolumn{2}{|c|}{ Temp } & \multicolumn{9}{|c|}{ Thermal conductivities, $\mu \mathrm{cal} / \mathrm{s}-\mathrm{cm}-\mathrm{K}$} \\
\hline $\mathrm{C}$ & $\mathrm{K}$ & $\mathrm{H}_{2} \mathrm{O}$ & $\mathrm{H}_{2}$ & $\mathrm{~N}_{2}$ & $\mathrm{He}$ & $\mathrm{Ar}$ & $\mathrm{CH}_{4}$ & $\mathrm{O}_{2}$ & $\mathrm{Ne}^{2}$ & $\mathrm{CO}$ \\
\hline 0 & 273 & 38.55 & 389.01 & 56.64 & 330.18 & 38.99 & 71.65 & 58.00 & 108.53 & 35.49 \\
\hline 10 & 283 & 40.19 & 400.33 & 58.39 & 338.56 & 40.06 & 75.10 & 59.94 & 111.23 & 37.41 \\
\hline 20 & 293 & 41.89 & 411.51 & 60.13 & 346.91 & 41.11 & 78.59 & 61.86 & 113.91 & 39.34 \\
\hline 30 & 303 & 43.63 & 422.56 & 61.85 & 355.23 & 42.16 & 82.13 & 63.77 & 116.56 & 41.27 \\
\hline 40 & 313 & 45.42 & 433.48 & 63.55 & 363.52 & 43.20 & 85.70 & 65.67 & 119.18 & 43.19 \\
\hline 50 & 323 & 47.25 & 444.27 & 65.23 & 371.78 & 44.23 & 89.31 & 67.55 & 121.76 & 45.11 \\
\hline 60 & 333 & 49.13 & 454.93 & 66.90 & 380.01 & 45.26 & 92.96 & 69.42 & 124.33 & 47.03 \\
\hline 70 & 343 & 51.05 & 465.47 & 68.55 & 388.20 & 46.27 & 96.65 & 71.27 & 126.86 & 48.94 \\
\hline 80 & 353 & 53.01 & 475.89 & 70.18 & 396.38 & 47.28 & 100.38 & 73.12 & 129.36 & 50.86 \\
\hline 90 & 363 & 55.01 & 486.19 & 71.80 & 404.52 & 48.28 & 104.15 & 74.95 & 131.84 & 52.77 \\
\hline 100 & 373 & 57.05 & 496.37 & 73.40 & 412.63 & 49.28 & 107.96 & 76.76 & 134.29 & 54.68 \\
\hline 110 & 383 & 59.13 & 506.43 & 74.98 & 420.71 & 50.26 & 111.80 & 78.57 & 136.72 & 56.58 \\
\hline 120 & 393 & 61.24 & 516.38 & 76.55 & 428.77 & 51.24 & 115.68 & 80.36 & 139.11 & 58.48 \\
\hline 130 & 403 & 63.39 & 526.23 & 78.10 & 436.79 & 52.22 & 119.59 & 82.14 & 141.49 & 60.38 \\
\hline 140 & 413 & 65.57 & 535.96 & 79.63 & 444.79 & 53.18 & 123.54 & 83.90 & 143.83 & 62.28 \\
\hline 150 & 423 & 67.79 & 545.59 & 81.15 & 452.76 & 54.14 & 127.53 & 85.66 & 146.15 & 64.17 \\
\hline 160 & 433 & 70.03 & 555.11 & 82.66 & 460.70 & 55.09 & 131.55 & 87.40 & 148.45 & 66.06 \\
\hline 170 & 443 & 72.30 & 564.53 & 84.15 & 468.62 & 56.03 & 135.60 & 89.13 & 150.72 & 67.94 \\
\hline 180 & 453 & 74.61 & 573.85 & 85.63 & 476.50 & 56.97 & 139.69 & 90.85 & 152.97 & 69.82 \\
\hline 190 & 463 & 76.94 & 583.08 & 87.09 & 484.36 & 57.90 & 143.80 & 92.56 & 155.20 & 71.70 \\
\hline 200 & 473 & 79.29 & 592.21 & 88.54 & 492.19 & 58.82 & 147.96 & 94.25 & 157.40 & 73.57 \\
\hline
\end{tabular}

Table 7-3. Calculated Gas Thermal Conductivities after Conversion to $\mathrm{W} / \mathrm{m}-\mathrm{K}$

\begin{tabular}{|c|c|c|c|c|c|c|c|c|c|c|}
\hline \multicolumn{2}{|c|}{ Temp } & \multicolumn{9}{|c|}{ Thermal conductivities, W/m-K } \\
\hline $\mathrm{C}$ & $\mathrm{K}$ & $\mathrm{H}_{2} \mathrm{O}$ & $\mathrm{H}_{2}$ & $\mathrm{~N}_{2}$ & $\mathrm{He}$ & $\mathrm{Ar}$ & $\mathrm{CH}_{4}$ & $\mathrm{O}_{2}$ & $\mathrm{Ne}$ & $\mathrm{CO}_{2}$ \\
\hline 0 & 273 & 0.01613 & 0.16277 & 0.02370 & 0.13815 & 0.01631 & 0.02998 & 0.02427 & 0.04541 & 0.01485 \\
\hline 10 & 283 & 0.01682 & 0.16750 & 0.02443 & 0.14166 & 0.01676 & 0.03142 & 0.02508 & 0.04654 & 0.01565 \\
\hline 20 & 293 & 0.01753 & 0.17218 & 0.02516 & 0.14515 & 0.01720 & 0.03288 & 0.02588 & 0.04766 & 0.01646 \\
\hline 30 & 303 & 0.01826 & 0.17680 & 0.02588 & 0.14863 & 0.01764 & 0.03436 & 0.02668 & 0.04877 & 0.01727 \\
\hline 40 & 313 & 0.01900 & 0.18137 & 0.02659 & 0.15210 & 0.01808 & 0.03586 & 0.02748 & 0.04986 & 0.01807 \\
\hline 50 & 323 & 0.01977 & 0.18589 & 0.02729 & 0.15555 & 0.01851 & 0.03737 & 0.02826 & 0.05095 & 0.01887 \\
\hline 60 & 333 & 0.02056 & 0.19035 & 0.02799 & 0.15900 & 0.01894 & 0.03890 & 0.02905 & 0.05202 & 0.01968 \\
\hline 70 & 343 & 0.02136 & 0.19476 & 0.02868 & 0.16243 & 0.01936 & 0.04044 & 0.02982 & 0.05308 & 0.02048 \\
\hline 80 & 353 & 0.02218 & 0.19912 & 0.02936 & 0.16585 & 0.01978 & 0.04200 & 0.03059 & 0.05413 & 0.02128 \\
\hline 90 & 363 & 0.02302 & 0.20343 & 0.03004 & 0.16925 & 0.02020 & 0.04358 & 0.03136 & 0.05516 & 0.02208 \\
\hline 100 & 373 & 0.02387 & 0.20768 & 0.03071 & 0.17265 & 0.02062 & 0.04517 & 0.03212 & 0.05619 & 0.02288 \\
\hline 110 & 383 & 0.02474 & 0.21190 & 0.03137 & 0.17603 & 0.02103 & 0.04678 & 0.03287 & 0.05720 & 0.02367 \\
\hline 120 & 393 & 0.02562 & 0.21606 & 0.03203 & 0.17940 & 0.02144 & 0.04840 & 0.03362 & 0.05821 & 0.02447 \\
\hline 130 & 403 & 0.02652 & 0.22018 & 0.03268 & 0.18276 & 0.02185 & 0.05004 & 0.03437 & 0.05920 & 0.02526 \\
\hline 140 & 413 & 0.02744 & 0.22425 & 0.03332 & 0.18610 & 0.02225 & 0.05169 & 0.03511 & 0.06018 & 0.02606 \\
\hline 150 & 423 & 0.02836 & 0.22828 & 0.03396 & 0.18944 & 0.02265 & 0.05336 & 0.03584 & 0.06115 & 0.02685 \\
\hline 160 & 433 & 0.02930 & 0.23226 & 0.03459 & 0.19276 & 0.02305 & 0.05504 & 0.03657 & 0.06211 & 0.02764 \\
\hline 170 & 443 & 0.03025 & 0.23621 & 0.03521 & 0.19607 & 0.02344 & 0.05674 & 0.03729 & 0.06306 & 0.02843 \\
\hline 180 & 453 & 0.03122 & 0.24011 & 0.03583 & 0.19937 & 0.02384 & 0.05845 & 0.03801 & 0.06400 & 0.02921 \\
\hline 190 & 463 & 0.03219 & 0.24397 & 0.03644 & 0.20266 & 0.02423 & 0.06017 & 0.03873 & 0.06494 & 0.03000 \\
\hline 200 & 473 & 0.03318 & 0.24779 & 0.03704 & 0.20594 & 0.02461 & 0.06191 & 0.03944 & 0.06586 & 0.03078 \\
\hline
\end{tabular}




\section{Sample calculation for conversion from $\mu \mathrm{cal} / \mathrm{s}-\mathrm{cm}-\mathrm{K}$ to $\mathrm{W} / \mathrm{m}-\mathrm{K}$}

The thermal conductivity of argon at $30^{\circ} \mathrm{C}(303 \mathrm{~K})$ is listed in Table 7-2 (per the above sample calculation) as $42.16 \mu \mathrm{cal} / \mathrm{s}-\mathrm{cm}-\mathrm{K}$, where one calorie is taken as a "thermochemical calorie" (4.184 joules, as listed by ASTM E380-92). Note that, while the reference (Yaws 1977) for Tables 7-1 and 7-2 does not state which convention it uses, the worst possible difference between some other convention that might have been used by [Yaws 1977] (if, indeed, only one convention is reflected in the that document's values) and the convention assumed for this conversion calculation would amount to $0.14 \%$ relative, which is considered insignificant.

$$
\begin{gathered}
42.16 \mu \mathrm{cal} / \mathrm{s} . \mathrm{cm} . \mathrm{K}=42.16 \times 10^{-6} \mathrm{cal} / \mathrm{s} . \mathrm{cm} . \mathrm{K} ; 42.16 \times 10^{-6} \mathrm{cal} / \mathrm{s} . \mathrm{cm} . \mathrm{K} \times 4.184 \mathrm{~J} / \mathrm{cal}= \\
\begin{array}{c}
1.764 \times 10^{-4} \mathrm{~J} / \mathrm{s} . \mathrm{cm} . \mathrm{K}=1.764 \times 10^{-4} \mathrm{~W} / \mathrm{cm} . \mathrm{K} ; 1.764 \times 10^{-4} \mathrm{~W} / \mathrm{cm} . \mathrm{K} \times 10^{+2} \mathrm{~cm} / \mathrm{m} \\
=.01764 \mathrm{~W} / \mathrm{cm}-\mathrm{K} \text { (see listing in Table } 7-3) .
\end{array}
\end{gathered}
$$

\begin{tabular}{|c|c|c|c|}
\hline \multicolumn{4}{|c|}{ Variation of thermal conductivity of worst case gas mixture of $\mathrm{He}(0.5 \mathrm{~mol} \% \mathrm{Ar})$} \\
\hline \multicolumn{4}{|c|}{ Based on approach recommended in Perry's 5th Ed (pg 3-244, Eqn 3-100) } \\
\hline & Conductivity of Worst Case Mixture & Conductivity Ratio Between Worst Case Mixture and $\mathrm{He}$ & \\
\hline $\mathrm{yHe}=$ & 0.995 & $\mathrm{MHe}=$ & 4 \\
\hline $\mathrm{yAr}=$ & 0.005 & $\mathrm{MAr}=$ & 39.95 \\
\hline & & & \\
\hline Temp, C & $\mathrm{W} / \mathrm{m}-\mathrm{K}$ & $\mathrm{k}_{\operatorname{mix}} / \mathrm{k}_{\mathrm{He}}$ & \\
\hline 0 & 0.1368 & 0.9906 & \\
\hline 10 & 0.1403 & 0.9906 & \\
\hline 20 & 0.1438 & 0.9906 & \\
\hline 30 & 0.1472 & 0.9906 & \\
\hline 40 & 0.1507 & 0.9906 & \\
\hline 50 & 0.1541 & 0.9906 & \\
\hline 60 & 0.1575 & 0.9906 & \\
\hline 70 & 0.1609 & 0.9906 & \\
\hline 80 & 0.1643 & 0.9906 & \\
\hline 90 & 0.1677 & 0.9906 & \\
\hline 100 & 0.1710 & 0.9906 & \\
\hline 110 & 0.1744 & 0.9906 & \\
\hline 120 & 0.1777 & 0.9906 & \\
\hline 130 & 0.1810 & 0.9906 & \\
\hline 140 & 0.1844 & 0.9906 & \\
\hline 150 & 0.1877 & 0.9906 & \\
\hline 160 & 0.1909 & 0.9906 & \\
\hline 170 & 0.1942 & 0.9906 & \\
\hline 180 & 0.1975 & 0.9906 & \\
\hline 190 & 0.2008 & 0.9906 & \\
\hline 200 & 0.2040 & 0.9906 & \\
\hline
\end{tabular}

Table 7-4. Calculated Thermal Conductivities for Worst Case Supply Gas 


\section{Sample calculation for worst case supply gas compositions listed by Table 7-4}

Equation 3-100 on page 3-244 of Perry's 5th Edition gives: $k_{m}=\sum y_{i} k_{i}\left(M_{i}\right)^{1 / 3} / \sum y_{i}\left(M_{i}\right)^{1 / 3}$ where $\mathrm{k}_{\mathrm{m}}$ is the thermal conductivity of the mixture $(\mathrm{W} / \mathrm{m}-\mathrm{K})$, $y_{i}$ is the mole fraction of the $i$ th component in the gas mixture, and $\mathrm{M}_{\mathrm{i}}$ is the molecular weight of the $\mathrm{ith}$ component in the gas mixture.

Table 7-3 lists the following thermal conductivities for argon and helium at $30^{\circ} \mathrm{C}$ :

$$
\begin{aligned}
& \mathrm{k}_{\mathrm{Ar}}=0.01764 \mathrm{~W} / \mathrm{cm}-\mathrm{K} ; \text { and } \\
& \mathrm{k}_{\mathrm{He}}=0.14863 \mathrm{~W} / \mathrm{cm}-\mathrm{K} .
\end{aligned}
$$

Finally: $\mathrm{M}_{\mathrm{Ar}}=39.95 \mathrm{~g} / \mathrm{mole}$, and $\mathrm{M}_{\mathrm{He}}=4 \mathrm{~g} / \mathrm{mole}$.

The conductivity of the worst [conductivity] case supply gas, $99.5 \mathrm{~mol} \% \mathrm{He}$ and $0.5 \%$ Ar, at $30^{\circ} \mathrm{C}$ will then be given by $\mathrm{k}_{\mathrm{m}}=\sum \mathrm{y}_{\mathrm{i}} \mathrm{k}_{\mathrm{i}}\left(\mathrm{M}_{\mathrm{i}}\right)^{1 / 3} / \sum \mathrm{y}_{\mathrm{i}}\left(\mathrm{M}_{\mathrm{i}}\right)^{1 / 3}=$ $\left[\left(\mathrm{y}_{\mathrm{Ar}} \mathrm{k}_{\mathrm{Ar}}\right)\left(\mathrm{M}_{\mathrm{Ar}}\right)^{1 / 3}+\left(\mathrm{y}_{\mathrm{He}} \mathrm{k}_{\mathrm{He}}\right)\left(\mathrm{M}_{\mathrm{He}}\right)^{1 / 3}\right] /\left[\mathrm{y}_{\mathrm{Ar}}\left(\mathrm{M}_{\mathrm{Ar}}\right)^{1 / 3}+\mathrm{y}_{\mathrm{He}}\left(\mathrm{M}_{\mathrm{He}}\right)^{1 / 3}\right]=$ $\left[0.005 \times 0.01764(39.95)^{1 / 3}+0.995 \times 0.14863(4)^{1 / 3}\right] /\left[0.005(39.95)^{1 / 3}+0.995(4)^{1 / 3}\right]=$ $\left[8.8200 \times 10^{-5}(39.95)^{1 / 3}+(0.14789)(4)^{1 / 3}\right] /\left[0.005(39.95)^{1 / 3}+0.995(4)^{1 / 3}\right]=$ $\left[8.8200 \times 10^{-5}(3.4185)+(0.14789)(1.5874)\right] /[0.005(3.4185)+0.995(1.5874)]=$ $[0.00030+0.23476] /[0.01709+1.57946)]=0.23506 / 1.59655=0.14723 \mathrm{~W} / \mathrm{m}-\mathrm{K}=$

$0.1472 \mathrm{~W} / \mathrm{m}-\mathrm{K}$ (see $30^{\circ} \mathrm{C}$ listing in Table 7-4).

Comparing the $0.14863 \mathrm{~W} / \mathrm{cm}-\mathrm{K}$ conductivity listed in Table 7-3 for pure helium at $30^{\circ} \mathrm{C}$ to the value obtained above for the worst case mixture at $30^{\circ} \mathrm{C}(0.14723 \mathrm{~W} / \mathrm{cm}-\mathrm{K})$, the conductivity ratio between the worst mixture and pure helium (at $30^{\circ} \mathrm{C}$ ) is:

$0.14723 / 0.14863=0.99058=\mathbf{0 . 9 9 0 6}\left(\right.$ see $30^{\circ} \mathrm{C}$ listing in Table 7-4). 
HNF-4702, Rev. 0

\subsection{IMPACT ON PARTICULATE GENERATION}

Based on the following discussions and/or calculations, no more than 169 grams of additional $\mathrm{UO}_{2}$ (134 grams from section 7.2.2 and 35 grams from section 7.2.3, below) would be generated within a safety basis MCO as the result of the impurities listed in Table 3-2. Considering the fact that a 169 gram increase represents only $5 \%$ of the 3255 gram contingency that is included in the 9765 gram grand total reported in Table 2-1 of [Sherrell 1998], it is not considered significant.

Because many steps in the vacuum drying process require that the MCO be continuously purged with helium, it is necessary to evaluate the nature and extent of any impacts that impurities in the helium might have on uranium corrosion rates during the drying process. Corrosion of freshly cleaned fuel assemblies will continue to generate uranium oxides as long as exposed uranium surfaces are in contact with either water or water vapor. The generated particulate is of concern because it represents most of the Material At Risk (MAR) in estimates used for evaluation of radiological releases for various accidents postulated by the CVDF and CSB Safety Analysis Reports (SAR)s, and to a lesser extent, because it can slightly increase the amount of water that remains within the MCO upon completion of the CVD process.

Post fuel-cleaning uranium corrosion is addressed by two different SNF Project documents. Calculations for uranium corroded between fuel cleaning at the basin and MCO draining at the CVD are provided by HNF-SD-W441-CN001, Spent Nuclear Fuel Inventory in Bulk MCO Water at the Cold Vacuum Drying Facility (Sherrell 1999a), while those for the balance of the cold vacuum drying process are provided (along with corrosion calculations for transport and storage) by HNF-3048, Post Fuel-Cleaning Corrosion of Uranium Within MCO Payloads (Sherrell 1998). Note that the title of [Sherrell 1998] is all inclusive because it includes a roll-up of the pre-MCO-draining corrosion estimates from [Sherrell 1999a].

In view of the fact that $97 \%$ of the safety basis pre-MCO-draining corrosion estimate (Sherrell 1999a) is attributed to situations where the fuel assemblies are completely covered with water, with little or no "sparging" of the water by the helium cover gas, the particulate generation evaluation is limited to estimating the impact of helium impurities on the post-MCO-draining uranium corrosion document (Sherrell 1998).

\subsubsection{Evaluation of Impurities Listed for the Air Ingress Case of Table 3-2}

Based on Figures 4-2 and 5-2 of the Uranium Oxidation Rate Summary for the Spent Nuclear Fuel Project (Pajunen 1999), the only impact from the air ingress case of Table 3-2 would be a reduction in the uranium corrosion rate.

Figure 4-2 of [Pajunen 1999] plots literature data versus inverse temperature for oxidation of uranium metal in moist, oxygen free, atmospheres, along with the best-fit, the design basis, and the safety basis correlations that were input to the Spent Nuclear Fuel Project Technical Databook (Reilly 1998). Figure 5-2 presents corresponding uranium corrosion data for moist air atmospheres. The above conclusion that the air ingress case of Table 3-2 would reduce uranium corrosion rates below what they would otherwise be for pure helium is based on the fact that the design basis corrosion rates plotted on Figure 4-2 (no oxygen) are ten times higher than those plotted on Figure 5-2 (moist air). 


\subsubsection{Evaluation of Impurities Listed for the Water Ingress Case of Table 3-2}

Based on the following discussions and calculations, the water ingress case of Table 3-2 would increase the calculated safety basis total (Sherrell 1998) for post-drain particulate generation from $6510 \mathrm{~g}$ to $6644 \mathrm{~g}$, for a net increase of 134 grams.

Table 7-5. Calculation of Incremental Particulate from Table 3-2 Water Case

\begin{tabular}{|c|c|c|c|c|c|c|c|c|}
\hline $\begin{array}{l}\text { MCO OPERATION } \\
\text { and } \\
\text { CVDF STEP NO. } \\
\text { (See Notes } 1 \& 2 \text { ) }\end{array}$ & $\begin{array}{l}\text { DURATION } \\
(\mathrm{hr})\end{array}$ & $\begin{array}{l}\mathrm{P}_{\mathrm{MCO}} \\
(\mathrm{kPa})\end{array}$ & $\begin{array}{l}\mathrm{P}_{\mathrm{Base}} \\
(\mathrm{kPa})\end{array}$ & $\underset{\text { (mole frac) }}{\mathrm{C}_{\mathrm{H} 20}}$ & $\begin{array}{l}\mathrm{P}_{\text {Add }} \\
(\mathrm{kPa})\end{array}$ & $\begin{array}{l}\mathrm{P}_{\mathrm{Rev}} \\
(\mathrm{kPa})\end{array}$ & $\underset{\left(\text { grams } \cup_{2}\right)}{\mathrm{G}_{\text {Baseline }}}$ & $\underset{\left(\text { grams } \cup_{2} \text { ) }\right.}{\mathrm{G}_{\text {Revised }}}$ \\
\hline $\begin{array}{l}\text { 1st Vac Dry Cycle } \\
(27)\end{array}$ & $\begin{array}{l}1.0 \\
1.0 \\
1.0 \\
1.0 \\
1.0 \\
1.0 \\
2.0\end{array}$ & $\begin{array}{r}17 \\
13 \\
10 \\
8 \\
8 \\
7 \\
7\end{array}$ & $\begin{array}{r}10.2 \\
6.0 \\
4.2 \\
2.6 \\
1.9 \\
1.5 \\
0.8\end{array}$ & $\begin{array}{l}0.005 \\
0.005 \\
0.005 \\
0.005 \\
0.005 \\
0.005 \\
0.005\end{array}$ & $\begin{array}{l}0.085 \\
0.065 \\
0.050 \\
0.040 \\
0.040 \\
0.035 \\
0.035\end{array}$ & $\begin{array}{r}10.29 \\
6.07 \\
4.25 \\
2.64 \\
1.94 \\
1.54 \\
0.84\end{array}$ & $\begin{array}{c}159 \\
111 \\
93 \\
80 \\
87 \\
77 \\
126\end{array}$ & $\begin{array}{c}160 \\
112 \\
94 \\
81 \\
88 \\
78 \\
129\end{array}$ \\
\hline Ist Thermal Reset (31) & 4.0 & $\begin{array}{c}129 \\
\text { (4 psig) }\end{array}$ & 10.0 & 0.005 & 0.645 & 10.645 & 912 & 941 \\
\hline $\begin{array}{l}\text { 2nd Vac Dry Cycle } \\
\text { (33) }\end{array}$ & $\begin{array}{l}3.0 \\
1.0\end{array}$ & $\begin{array}{l}6 \\
6\end{array}$ & $\begin{array}{l}0.7 \\
0.3\end{array}$ & $\begin{array}{l}0.005 \\
0.005\end{array}$ & $\begin{array}{c}0.030 \\
0.03\end{array}$ & $\begin{array}{l}0.730 \\
0.330\end{array}$ & $\begin{array}{c}198 \\
44\end{array}$ & $\begin{array}{c}202 \\
46\end{array}$ \\
\hline $\begin{array}{c}\text { 2nd Thermal Reset } \\
\text { (37) }\end{array}$ & 4.0 & 129 & 8.0 & 0.005 & 0.645 & 8.645 & 892 & 927 \\
\hline $\begin{array}{l}\text { Cool Down and } \\
\text { Close Ports }(43-44)\end{array}$ & $\begin{array}{l}1.2 \\
1.0 \\
1.0\end{array}$ & $\begin{array}{l}129 \\
129 \\
129\end{array}$ & $\begin{array}{l}0.8 \\
1.2 \\
1.7\end{array}$ & $\begin{array}{c}0.005 \\
0.005 \\
-0- \\
\text { See Note } 3\end{array}$ & $\begin{array}{c}0.645 \\
0.645 \\
-0- \\
\text { See Note } 3\end{array}$ & $\begin{array}{c}1.445 \\
1.845 \\
1.7 \\
\text { See Note } 3\end{array}$ & $\begin{array}{r}115 \\
63 \\
38\end{array}$ & $\begin{array}{c}155 \\
78 \\
38 \\
\text { See Note } 3\end{array}$ \\
\hline $\begin{array}{l}\text { TOTAL PARTICULATE } \\
\text { (Listed Steps Only) }\end{array}$ & \multicolumn{6}{|c|}{$\begin{array}{l}\text { The } 3 \mathrm{~kg} \text { total shown for the listed steps (those impacted by impure } \mathrm{He} \text { ) } \\
\text { represents less than half of the amount calculated by [Sherrell 1998] for } \\
\text { the complete drying process, and less than a third of the } 9.8 \mathrm{~kg} \text { reported } \\
\text { post-drain total, which includes over } 3 \mathrm{~kg} \text { of contingency. }\end{array}$} & 2,995 & 3,129 \\
\hline \multicolumn{5}{|c|}{ INCREMENTAL. UO ${ }_{2}$ GENERATED BY MOISTURE IN HELIUM SUPPLY } & \multicolumn{4}{|c|}{$3,129 \mathrm{~g}-2,995 \mathrm{~g}=134 \mathrm{~g}$} \\
\hline
\end{tabular}

Notes:

1. No incremental particulate will accrue from moisture in the supply helium during the PWC/SCHe Purge (Step 26), because the MCO atmosphere will already be saturated with moisture from standing water throughout this operation, regardless of the helium supply purity.

2. No incremental particulate will accrue from moisture in the supply helium during Steps 40 and 42 (1st \& 2 nd Rebound Tests) or during Step 41 (Proof-of-Dryness) because the MCO will contain essentially no helium during these fully evacuated, zero purge flow, operations

3. No incremental particulate will accrue from moisture in the supply helium after the first 2.2 hours of the cool-down cycle (Step 43), or during any subsequent CVDF operations, because the total quantity of helium (and, therefore, moisture) introduced into the MCO between completion of the fully evacuated 2 nd rebound test (Step 42) and shipment of the MCO to the CSB (Step 67) is limited by the maximum $\mathrm{MCO}$ backfill pressure (see section 7.2.2.2.3 below). Also note that this evaluation takes all of the impurity moisture from the maximum helium backfill quantity "up front," even though most of the backfill gas will actually be introduced after completion of the cool-down step. 
7.2.2.1 Basis for Current Post-Drain Particulate Generation Estimate. Table 2-1 of [Sherrell 1998] summarizes safety basis uranium corrosion calculations and results for all CVDF "postdrain" operations, i.e., those operations that occur after the bulk water is drained from an MCO.

7.2.2.1.1 CVDF Post Drain Operations Summary. Post-drain CVDF operations, as summarized in [Sherrell 1998], consist of:

1. A positive gage pressure purge (the "PWC/SCHe Purge") that occurs immediately after MCO draining, at which point any water vapor introduced into the $\mathrm{MCO}$ by the helium will be of no consequence because the MCO's contents will be covered and/or saturated with water;

2. The first vacuum drying cycle ( 8 hrs duration), most of which involves essentially dry fuel surfaces surrounded by non-saturated helium (where any water vapor that is initially within the continuous helium purge could impact uranium corrosion rates), and during which the total system pressure ranges from roughly 0.15 to $0.06 \mathrm{~atm}$ (i.e., a "rough vacuum");

3. The first of two "thermal reset" steps ( 4 hrs duration) that purge the MCO with helium at a positive gage pressure to allow fuel temperatures to equalize, and during which the helium is expected to remain well below the saturation level (i.e., any water vapor that is initially within the continuous helium purge could impact uranium corrosion rates);

4. The second vacuum drying cycle ( 4 hrs duration), wherein both the total system pressure and the partial pressure of water are taken to be lower than they were during the initial vacuum drying cycle (which means that the relative impact of any water vapor within the helium purge gas would be even greater during this step than it would be during the first vacuum drying cycle);

5. A second thermal reset step that is essentially identical to the first one, with the exception that the fuel is taken to be at a higher temperature, while the partial pressure of water is taken to be lower (which means that the relative impact of any water vapor impurity within the helium purge would be even greater during this step than it would be during the first thermal reset step);

6. A series of totally evacuated steps (one $19 \mathrm{hr}$ duration "proof-of-dryness test" and two $1 \mathrm{hr}$ duration "pressure rebound tests," that immediately precede and follow the "proof test"), during which there can be no impact from impurities within the helium supply because the MCO contains essentially no helium under these conditions; and

7. A series of no-purge, positive gage pressure operations (MCO cool-down, He leak test, cask preparation, etc.) during which the total amount of helium (and therefore, helium impurities) within the MCO will be limited by the maximum backfill pressure (see section 7.3.2.2.3). 
7.2.2.1.2 The Reaction Rate Equation. The project's technical databook (Reilly 1998) lists the reaction rate of uranium in oxygen free water vapor as: weight gain [mg] $/ \mathrm{hr}=\mathrm{A}_{\mathrm{s}} \zeta \mathrm{K}$, where

$$
\begin{aligned}
& \mathrm{A}_{\mathrm{s}}=\text { the exposed surface area }\left(\mathrm{cm}^{2}\right), \\
& \zeta=\text { the reaction enhancement factor (dimensionless), and } \\
& \qquad \begin{array}{r}
\log \mathrm{K}=4.33-2144 / \mathrm{T}+0.5 \log \mathrm{P} \text {, where } \\
\mathrm{P} \text { is the partial pressure of water vapor in } \mathrm{kPa}, \\
\mathrm{T} \text { is in Kelvins, and } \\
\mathrm{K}=\text { mg of weight gained per } \mathrm{cm}^{2} \text {, per hour. }
\end{array}
\end{aligned}
$$

For the purposes of this evaluation, the only parameter of interest is the vapor pressure of water because none of the other parameters (temperature, surface area, etc.) would be affected to any significant extent by the additional water vapor. In particular, there will be no significant impact on the temperature, which is the only parameter that could be affected by the additional water vapor, either from its affect on the conductivity of the helium (see section 7.1, above) or from its affect on reaction heat rates (see section 7.4, below). Therefore, based on the general form of the above equation for $\mathrm{K}$ (where $\log \mathrm{K}=\mathrm{X}+0.5 \log \mathrm{P}$ ), the additional amount of particulate formed will be proportional to the square root of the ratio between the vapor pressure used by [Sherrell 1998 ] and the higher vapor pressure that would result from the $0.5 \%$ water vapor content of the evaluated helium supply:

$$
\begin{aligned}
G_{R e v}= & \left(G_{\text {Base }}\right) \times\left(P_{R e v} / P_{\text {Base }}\right)^{1 / 2} \text {, where } \\
& \left.G_{R e v} \text { is the revised generated particulate estimate (as grams of } \mathrm{UO}_{2}\right), \\
& G_{\text {Base }} \text { is the original generated particulate estimate from [Sherrell 1998], } \\
& P_{R e v} \text { is the revised partial pressure of water vapor }(\mathrm{kPa}), \text { and } \\
& P_{\text {Base }} \text { is the original partial pressure of water vapor used by [Sherrell 1998] . }
\end{aligned}
$$

7.2.2.1.3 Bases for Partial Pressures Used by [Sherrell 1998] . Section 4.2.1.2 of [Sherrell 1998] establishes the partial pressures that are used for that document's calculations, based on Appendix Q of FAI/98-33, Rev 2 Simulation of Normal and Off-Normal Multi-canister Overpack Behavior (Plys 1998), which plots total system pressures and mole fractions of water vapor versus time for various cold vacuum drying operations.

For Vacuum Drying Cycles: Partial pressures were obtained for vacuum operations (i.e., the 1 st and 2 nd vacuum drying cycles) by multiplying the mole fractions listed in Appendix Q of [Plys 1998] by the corresponding total system pressures. The resulting pressure listings from Table 2-1 of [Sherrell 1998] are reproduced below: 
Step 27 -- First Vacuum Drying Cycle (8hours total)

$60 \mathrm{~min}$ at $10.2 \mathrm{kPa}$

$60 \mathrm{~min}$ at $6.0 \mathrm{kPa}$

$60 \mathrm{~min}$ at $4.2 \mathrm{kPa}$

$60 \mathrm{~min}$ at $2.6 \mathrm{kPa}$

$60 \mathrm{~min}$ at $1.9 \mathrm{kPa}$

$60 \mathrm{~min}$ at $1.5 \mathrm{kPa}$

$120 \mathrm{~min}$ at $0.8 \mathrm{kPa}$

Step 33 -- Second Vacuum Drying Cycle (4 hrs total)

$180 \min$ at $0.7 \mathrm{kPa}$

$60 \mathrm{~min}$ at $0.3 \mathrm{kPa}$

For Thermal Reset Purge Cycles: [Sherrell 1998] uses partial pressures of $10 \mathrm{kPa}$ and $8 \mathrm{kPa}$, respectively, for the 1 st. and 2 nd. thermal reset cycles, based on water vapor concentrations from the "He-purge-only" plot on page Q-8 of [Plys 1998]. In this case the plotted value for \% steam is numerically equal to the partial pressure of water vapor (as $\mathrm{kPa}$ ) because the total system pressure is roughly $100 \mathrm{kPa}$ (i.e., $\sim 1 \mathrm{~atm}$ ). The $10 \mathrm{kPa}$ and $8 \mathrm{kPa}$ values amount to conservative allowances, as opposed to estimates, because the MCO will contain much less free water during the actual thermal reset cycles then is reflected in the "He-purge-only" plot of [Plys 1998], which is not preceded by any vacuum drying steps.

For Cask/MCO Cool Down Operation and Balance of CVD Process: [Sherrell 1998] conservatively allowed for the partial pressure of water vapor to increase at the rate of 0.4 $\mathrm{kPa} / \mathrm{hr}$ during the cool down operation (CVD steps 43 thru 44). Both the $0.4 \mathrm{kPa} / \mathrm{hr}$ rate of increase and the $0.8 \mathrm{kPa}$ value used for the first hour of the cool down operation were based on the 3 torr $(0.4 \mathrm{kPa})$ maximum acceptable pressure rise allowed during the one hour duration final pressure rebound test (CVD Step 42) that immediately precedes the cool down operation. The resulting pressure listings are reproduced below from Table 2-1 of [Sherrell 1998]:

Steps 43 thru $44--$ Cool Down to $25^{\circ} \mathrm{C}$ ( 3 hrs 10 min total)

$60 \mathrm{~min}$ at $0.8 \mathrm{kPa}$

$60 \mathrm{~min}$ at $1.2 \mathrm{kPa}$

$70 \mathrm{~min}$ at $1.7 \mathrm{kPa}$

Steps 45 thru 54 - MCO Helium Leak Test ( $3 \mathrm{hrs} 30 \mathrm{~min}$ total)

$120 \mathrm{~min}$ at $2.5 \mathrm{kPa}$

$90 \mathrm{~min}$ at $3.1 \mathrm{kPa}$

Steps 55 thru 57 -- Transport Cask Preparation (1 hr 45 min total)

$105 \mathrm{~min}$ at $3.8 \mathrm{kPa}$ 
Steps 58 thru 67 -- Prepare Transporter/Leave CVDF (1 hr 15 min total)

$75 \mathrm{~min}$ at $4.3 \mathrm{kPa}$

Note: The current draft revision of the CVD operations manual (Irwin 1999b) has essentially doubled the time allotted for Steps 43 through 44, however (as documented below) the 50\% contingency allowance of [Sherrell 1998] is more than adequate to cover the additional calculated particulate quantity that would result if [Sherrell 1998] were revised to address the additional time. In any case, the extended cool down time will have no impact on the results of this helium impurity impact calculation because the incremental particulate generation that occurs after completion of Step 37 (the last thermal reset cycle) will not be dependent on time but will, instead, be limited by the maximum possible helium back fill quantity. See below.

7.2.2.2 Incremental Post-Drain Particulate Generation from He Impurities. Quantitative estimates of additional particulate that would be generated by the $0.5 \%$ water vapor content associated with the water ingress case of Table 3-2 are developed below.

\subsection{Calculation of Revised Partial Pressures for Vacuum Drying Cycles}

$P_{\text {Rev }}=P_{\text {Base }}+P_{\text {Add }}$, where

$P_{R e v}$ is the revised partial pressure of water $(\mathrm{kPa})$,

$P_{\text {Base }}$ is the original partial pressure of water used by [Sherrell 1998], and

$\mathrm{P}_{\mathrm{Add}}$ is the additional partial pressure that accrues from water in the helium supply.

$\mathrm{P}_{\mathrm{Add}}=\mathrm{P}_{\mathrm{MCO}} \times \mathrm{C}_{\mathrm{H} 2 \mathrm{O}}$, where

$\mathrm{P}_{\mathrm{MCO}}=$ MCO pressure -- from "MCO Pressure" plot on page Q-5 of [Plys 1998]

$\mathrm{C}_{\mathrm{H} 2 \mathrm{O}}=$ concentration (mole fraction) of water in helium supply -- fixed at 0.005 . 
7.2.2.2.2 Sample Calculation for $\mathbf{G}_{\mathrm{Rev}}$. The following sample uses and/or calculates the values listed on the top line of Table 7-5. These are listed below, along with the sample calculation(s) and the applicable column heading from Table 7-5:

MCO OPERATION and CVDF STEP NO. -- 1 st Vac Dry Cycle (27),

DURATION (Hr) -- 1.0 \{i.e., this covers the 1 st hour of the eight hour long drying step ,

$$
\mathrm{P}_{\mathrm{MCO}}(\mathrm{kPa})--17
$$$$
\mathrm{P}_{\text {Base }}(\mathrm{kPa}) \quad--10.2 \text {, }
$$$$
\mathrm{C}_{\mathrm{H} 2 \mathrm{O}} \text { (mole frac) -- } 0.005 \text {, }
$$$$
\mathrm{P}_{\text {Add }}(\mathrm{kPa})--0.09\{\text { i.e., } 17 \mathrm{kPa} \times 0.005=0.085 \text {, or } 0.09 \mathrm{kPa}\} \text {, }
$$$$
\left.P_{\text {Rev }}(\mathrm{kPa})-10.29 \text { i.e., } 10.2 \mathrm{kPa}+0.09 \mathrm{kPa}=10.29 \mathrm{kPa}\right\} \text {, }
$$$$
\mathrm{G}_{\text {Base }}\left(\text { grams } \mathrm{UO}_{2}\right)--159 \text {, }
$$$$
\mathrm{G}_{\mathrm{Rev}}\left(\text { grams UO } \mathrm{U}_{2}\right)--160 \text { i.e., } \mathrm{G}_{\mathrm{Rev}}=\mathrm{G}_{\mathrm{Base}}\left(\mathrm{P}_{\mathrm{Rev}} / \mathrm{P}_{\mathrm{Base}}\right)^{1 / 2} \text {, }
$$

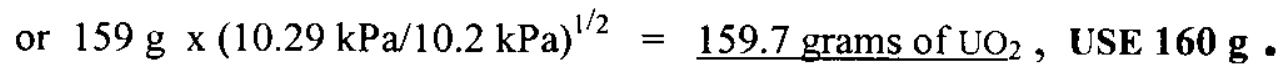

7.2.2.2.3 Maximum Incremental Particulate Generation After 2nd Thermal Reset. No incremental particulate (i.e., additional particulate that accrues from water in the supply helium) will be generated during the 1 st Rebound Test (Step 40), which occurs almost immediately after the 2nd Thermal Reset operation (Step 37), nor during the subsequent Proof-of-Dryness Test (Step 41), nor during the 2nd Rebound Test (Step 42), because the MCO will contain essentially no helium during these fully evacuated, zero purge flow, operations.

Upon successful completion of the 2nd Rebound Test, the MCO is backfilled with helium and maintained at a positive gage pressure (up to 4 psig -- $129 \mathrm{kPa}$, abs) for 6 hours (Irwin 1999b) while chilled water is circulated through the cask/MCO annulus to ensure that the average gas temperature of a worst case high heat $\mathrm{MCO}$ will be no more than $50^{\circ} \mathrm{C}$ when the final backfill pressure is established (Sherrell 1999b). Once the chilled water circulation requirements (chiller outlet temperature, flow rate, and time) have been satisfied, the MCO's backfill helium is "topped off" at a maximum pressure of 12.5 psig (after allowing for instrument error, etc.) and the MCO backfill port valve is closed. Based on the above maximum pressure (12.5 psig), and on the conservative assumption that the gas temperature within a zero decay heat MCO could be as low as $0^{\circ} \mathrm{C}$ when it is backfilled [Sherrell 1999b] has established a 41.3 mol "maximum" backfill gas inventory for a $500 \mathrm{~L}$ (i.e., minimum) void space MCO. 
The $41.3 \mathrm{~mol}$ maximum backfill gas inventory is appropriate for [Sherrell 1999b], which combines it with the maximum hydrogen inventory expected for any $\mathrm{MCO}$, and then uses the resulting total inventory to calculate the worst case maximum pressure for a minimum void space MCO. However, that inventory can not be used here, because this calculation must address the maximum backfill gas inventory of a maximum void space $\mathrm{MCO}$, as opposed to the resulting pressure contribution for a minimum void space $\mathrm{MCO}$.

Section 4.2.2 of the MCO Loading and Cask Loadout Technical Manual (Praga 1998), calculates MCO void volumes for various payload configurations. However, all of the configurations addressed by that document (e.g., five fuel baskets and no scrap baskets, three fuel baskets and two scrap baskets, etc.) assume that the MCO is fully loaded. As a result the maximum void volume listed by Table 4.2.2-1 of that document is $563 \mathrm{~L}$. For the purposes of this document, the following calculations are conservatively based on a maximum backfill gas inventory of 78.7 mol, which, in turn is based on the $953 \mathrm{~L}$ void volume listed by [Praga 1998] for an empty MCO (even though that MCO could contain no uranium, and therefore no generated particulate):

$$
41.3 \mathrm{~mol}(953 \mathrm{~L} / 500 \mathrm{~L})=78.7 \mathrm{~mol} \text {. }
$$

Based on the above, the total amount of moisture introduced into a worst case maximum void volume MCO by the backfill gas could not exceed:

$$
\text { (0.005 mol } \mathrm{H}_{2} \mathrm{O} / \text { gmol supply gas) }(78.7 \mathrm{~mol})=0.39 \mathrm{~mol} \mathrm{H}_{2} \mathrm{O} \text {, USE } 0.4 \text { mol. }
$$

At $1 / 2 \mathrm{~mol} \mathrm{O}_{2}$ per mol of $\mathrm{H}_{2} \mathrm{O}, 0.4 \mathrm{~mol}$ of $\mathrm{H}_{2} \mathrm{O}$ would produce, at most, $0.2 \mathrm{~mol}$ of $\mathrm{UO}_{2}$, which, at

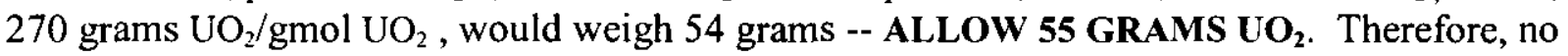
more than 55 grams of incremental $\mathrm{UO}_{2}$ can accrue from Steps 43 and 44, regardless of the amount that is calculated from the rate enhancement equation.

Finally, based on the assumption that the corrosion rate continues to be enhanced to the same degree until all of the incremental moisture has been consumed, even though the amount of rate enhancement will actually decrease as the reaction proceeds, the values listed by Table 7-5 for Steps 43 and 44 are obtained as shown below (see section 7.3.2.2, above, for definitions of the parameters). Again, note that although the current operations manual requires a 6 hour cooldown period whereas the calculation below is based on the 3 hour duration currently addressed by [Sherrell 1998], both the calculated and the actual maximum amount of incremental particulate that accrues from moisture within the supply gas will be unaffected by the extended cool-down time. This is demonstrated by the following calculation itself, which is limited by the maximum backfill volume, as opposed to time. 
MCO OPERATION and CVDF STEP NO. -- Cool Down and Close Ports (43 - 44),

DURATION (Hr) -- 1.2 \{i.e., the first row of values listed for these steps\},

$\mathrm{P}_{\mathrm{MCO}}(\mathrm{kPa})--129$,

$\mathrm{P}_{\text {Base }}(\mathrm{kPa})--0.8$,

$\mathrm{C}_{\mathrm{H} 2 \mathrm{O}}$ (mole frac) --0.005 ,

$P_{\text {Add }}(\mathrm{kPa})--0.65$ i.e., $\left.129 \mathrm{kPa} \times 0.005=0.65 \mathrm{kPa}\right\}$,

$P_{\text {Rev }}(\mathrm{kPa})-1.45$ \{i.e., $\left.0.8 \mathrm{kPa}+0.65 \mathrm{kPa}=1.45 \mathrm{kPa}\right\}$,

$\mathrm{G}_{\mathrm{Base}}\left(\right.$ grams $\left.\mathrm{UO}_{2}\right)--115$,

$\left.\mathrm{G}_{\mathrm{Rev}}(\text { grams UO })_{2}\right)--155$ i.e., $\mathrm{G}_{\mathrm{Rev}}=\mathrm{G}_{\text {Base }}\left(\mathrm{P}_{\mathrm{Rev}} / \mathrm{P}_{\mathrm{Basc}}\right)^{1 / 2}$,

or $115 \mathrm{~g} \mathrm{x}(1.45 \mathrm{kPa} / 0.8 \mathrm{kPa})^{1 / 2}=154.8{\text { grams of } \mathrm{UO}_{2}}_{2}$, USE $155 \mathrm{~g}$.

Calculated Incremental Particulate (this time period): $155-115=\mathbf{4 0}$ grams

DURATION (Hr) -- 1.0 \{i.e., the second row of values listed for these steps\},

$\mathrm{P}_{\mathrm{MCO}}(\mathrm{kPa})--129$

$\mathrm{P}_{\text {Base }}(\mathrm{kPa})-1.2$,

$\mathrm{C}_{\mathrm{H} 2 \mathrm{O}}$ (mole frac) -- 0.005 ,

$P_{\text {Add }}(\mathrm{kPa})--0.65\{$ i.e., $129 \mathrm{kPa} \times 0.005=0.65 \mathrm{kPa}\}$,

$P_{\text {Rev }}(\mathrm{kPa})--1.85$ \{i.e., $1.2 \mathrm{kPa}+0.65 \mathrm{kPa}=1.85 \mathrm{kPa}$,

$\mathrm{G}_{\text {Base }}\left(\right.$ grams $\left.\mathrm{UO}_{2}\right)$-- 63 ,

$\mathrm{G}_{\mathrm{Rev}}\left(\operatorname{grams} \mathrm{UO}_{2}\right)-\mathrm{G}_{\mathrm{Rev}}=\mathrm{G}_{\mathrm{Base}}\left(\mathrm{P}_{\mathrm{Rev}} / \mathrm{P}_{\mathrm{Base}}\right)^{1 / 2}$, or $63 \mathrm{~g} \times(1.85 \mathrm{kPa} / 1.2 \mathrm{kPa})^{1 / 2}=78.2$ grams of $\mathrm{UO}_{2}$.

Calculated Incremental Particulate (this time period): $78-63=15$ grams. 


\section{Confirm Calculated Incremental Particulate Within Excess $\mathrm{H}_{2}$ O Inventory:}

Calculated Incremental Particulate (so far), based on the above rate enhancement calculation: $40 \mathrm{~g}+15 \mathrm{~g}=\mathbf{5 5}$ grams

Maximum Amount That Can Accrue from $\mathrm{H}_{2} \mathrm{O}$ Within Backfill Gas, based on the maximum quantity of additional $\mathrm{H}_{2} \mathrm{O}(0.4 \mathrm{~mol})$ that could be introduced into any $\mathrm{MCO}$ by the backfill gas (see the first two pages of this section) - 55 grams

Therefore, based on the simplifying assumption that the degree of rate increase will remain constant until all of the additional water has been consumed, no incremental particulate will be generated after the first 2.2 hours of the cooldown cycle. Or, to put it another way, no more than 55 grams of incremental particulate will accrue after the 2 nd thermal reset cycle as a result of moisture within the supply gas, regardless of how long it takes to complete the balance of the CVD process.

\subsubsection{Evaluation of Worst Case Impurities Other Than Water or Air}

In addition to the oxygen, nitrogen or water vapor concentrations listed under air ingress and water vapor ingress, Table 3-2 also incorporates the maximum impurity levels listed by Table 31 as the "Evaluated Impurity Basis" for vendor supplied helium. These include: methane, at 2 ppm (plus an additional $8 \mathrm{ppm}$ from plant); neon, at $300 \mathrm{ppm}$; hydrogen, at $10 \mathrm{ppm}$; and carbon dioxide, at $10 \mathrm{ppm}$ (note that Table 3-2 lists $\mathrm{CO}_{2}$ at $11 \mathrm{ppm}$ for the air ingress case -- see the sample calculation in section 3.2.2 for the bases), and finally (for the purposes or this section) nitrogen, at $60 \mathrm{ppm}$. Nitrogen is specifically addressed in this section instead of assuming that it has already been addressed by the air ingress case discussed in section 7.2.1 because that discussion is based on the lower overall corrosion rate that is observed in moist air (i.e., in the presence of oxygen) as compared to moist inert gas.

Section 7.1 above concludes that the worst case gas composition $(99.5 \mathrm{~mol} \% \mathrm{He})$ allowed for delivery to an MCO (Irwin 1999a) would not significantly degrade the thermal conductivity of the helium, even if the other $0.5 \mathrm{~mol} \%$ were assumed to be argon, which is the worst case gas for thermal conductivity. It follows that fuel temperatures will not be significantly higher as a result of any thermal conductivity loss that might be associated with the above listed impurities. Therefore, this evaluation is limited to reactions between those impurities and the uranium, which eliminates neon as a particulate source because it is essentially inert.

With respect to the $10 \mathrm{ppm}$ hydrogen content, and any hydrogen that might accrue from radiolysis of the methane (which, at $10 \mathrm{ppm}$, would be equivalent to $20 \mathrm{ppm}$ of hydrogen), normal hydrogen levels within the MCO are expected to exceed those values by many orders of magnitude as the result of water vapor/uranium reactions. Therefore, no additional uranium hydrides are expected to result from impurities within the supply gas. 
Based on the above logic, the only additional uranium corrosion that might occur as the result of impurities other than water vapor or air would be limited to that caused by reaction (either direct or indirect) with the carbon dioxide and methane (note that the $11 \mathrm{ppm}$ value used for carbon dioxide is actually from the air-ingress case of Table 3-2), and by reaction with the $60 \mathrm{ppm}$ nitrogen inventory without the (possibly) mitigating influence of a $1,000 \mathrm{ppm}$ oxygen inventory .

Figure 27 of $A$ Review of the Rates of Reaction of Unirridiated Uranium in Gaseous Atmospheres (Pearce 1989) provides reaction rate versus temperature curves (actually data range envelopes) for uranium in various atmospheres, including dry air, steam, nitrogen, $\mathrm{CO}$, and $\mathrm{CO}_{2}$. While the temperature scale covers the range from $0^{\circ} \mathrm{C}$ to $1400^{\circ} \mathrm{C}$, none of the envelopes extend below approximately $100^{\circ} \mathrm{C}$, and only those for dry air and steam extend down that far. The data range envelope for $\mathrm{CO}_{2}$ is shown down to approximately $200^{\circ} \mathrm{C}$, while those for nitrogen and $\mathrm{CO}$ are shown down to approximately $300^{\circ} \mathrm{C}$. Despite the limitations of the figure in the temperature range from $40^{\circ} \mathrm{C}$ to $200^{\circ} \mathrm{C}$ (i.e., the range applicable to this document), a number of conclusions can still be drawn from the figure.

Based on the fact that the reaction rates shown for uranium in dry air are always well above those shown for nitrogen, any particulate generation that might accrue from the $60 \mathrm{ppm}$ nitrogen inventory of the vendor supplied helium should be enveloped by the amount that would accrue from the air-ingress case of Table 3-2, which, itself, would be enveloped by the water-ingress case evaluated in section 7.2.2 (see section 7.21 for a discussion of the air-ingress case). Therefore, the $60 \mathrm{ppm}$ nitrogen inventory can be ignored.

While the data range envelopes for carbon dioxide, carbon monoxide, and nitrogen appear to intermingle as they approach the temperature range of interest, the reaction rates shown for carbon dioxide generally exceed those shown for nitrogen over the entire temperature range covered by the figure. Therefore it is considered prudent to convert all of the available $\mathrm{CO}_{2}$ into $\mathrm{UO}_{2}$ on a mole-for-mole basis. And, because additional carbon dioxide could be formed from methane, as the result of radiolysis of both water and methane, followed by recombination of the resulting carbon and oxygen, the calculations also treat the $10 \mathrm{ppm}$ of $\mathrm{CH}_{4}$ as $10 \mathrm{ppm}$ of $\mathrm{CO}_{2}$, for an equivalent total of $11+10=21 \mathrm{ppm}$ of $\mathrm{CO}_{2}$.

The Cold Vacuum Drying Proof of Performance (First Article Testing) Test Results document (McCracken 1999) lists the nominal quantity of helium per MCO as 3,300 std. $\mathrm{ft}^{3}$ (scf) which actually represents the helium used for both nominal and worst case fuel configurations (pristine fuel required considerably less helium). Despite that observation, and the fact that some of that helium is used for other purposes (purging lines, etc.) this evaluation is based on a throughput of 5,000 scf (i.e., it includes a $50 \%$ contingency allowance on top of a conservative estimate):

$5,000 \mathrm{scf} \times 28.32 \mathrm{~L} / \mathrm{ft}^{3} \times 273 \mathrm{~K}\left[0^{\circ} \mathrm{C}\right] / 289 \mathrm{~K}\left[60^{\circ} \mathrm{F}\right] \times 1 / 22.4 \mathrm{~L}$ per mole $=5972$ moles --- USE 6,000 moles;

6,000 moles $\times 21 \mathrm{ppm} \mathrm{CO}_{2}=6,000 \times 21 \times 10^{-6}$ moles $=0.126$ moles $\mathrm{CO}_{2}$, which is equivalent to 0.126 moles $\mathrm{UO}_{2}$--- USE 0.13 moles $\mathrm{UO}_{2}$;

0.13 moles $\mathrm{UO}_{2}$ at 270 grams per mole $=35$ grams of additional $\mathrm{UO}_{2}$. 


\subsection{IMPACT ON PEAK HYDROGEN GENERATION RATES}

Based on the following discussions and calculations, the worst case supply gas composition for hydrogen generation (the water ingress case of Table 3-2) would have no impact on peak hydrogen generation rates currently reported for MCOs. See section 7.7, below, for an evaluation of helium impurity impacts on the initial hydrogen inventory of a post-CVDF MCO.

Hydrogen generation rates within MCOs are specifically addressed by HNF-2458, Design Basis Hydrogen Generation Rates in the Cold Vacuum Drying Facility (Pajunen 1998). Table 2-1 of that document reports peak rates for a bounding surface area MCO during normal and off-normal operations, listing them as $1.9 \times 10^{-3} \mathrm{~g} / \mathrm{sec}$ and a $2.4 \times 10^{-3} \mathrm{~g} / \mathrm{sec}$ respectively.

\subsubsection{Evaluation of Impurities Listed for the Air Ingress Case of Table 3-2}

While oxygen, carbon dioxide, and even nitrogen, are capable of reacting with uranium, overall reaction rates are very low in the presence of air (see section 7.2.1), and none of the reactions generates hydrogen (see section 7.2.3). Therefore, none of the impurities associated with the air ingress itself would be expected to impact hydrogen generation rates. See section 7.3.3 for an evaluation of those impurities listed for the air ingress case of Table 3-2 that are not associated with the air ingress itself.

\subsubsection{Evaluation of Impurities Listed for the Water Ingress Case of Table 3-2}

The following subsections evaluate impacts on the values reported by [Pajunen 1998] for bounding normal and bounding off-normal hydrogen generation rates, based on a worst case assumption that the entire $0.5 \mathrm{~mol} \%$ impurity inventory consists of water vapor. See section 7.3.3, below, for an evaluation of impurities that are not associated with the water ingress itself.

7.3.2.1 Impact on Bounding Peak Rate for Normal Operations. Section 5.2.7 of [Pajunen 1998] obtains the $1.9 \times 10^{-3} \mathrm{~g} / \mathrm{sec}$ peak rate for normal operations via the following calculation, which is excerpted from [Pajunen 1998].

Based on a $50 \mathrm{~mol} \%$ steam concentration within an $\mathrm{MCO}$ at a total system pressure of $15.8 \mathrm{kPa}$, with fuel temperatures all at approximately $50{ }^{\circ} \mathrm{C}$, the peak rate is calculated as follows:

Calculation of Peak Hydrogen Generation Rate@50 ${ }^{\circ} \mathrm{C}$

$\mathrm{P}_{\mathrm{S}}=0.5 \times 15.8 \mathrm{kPa}=7.9 \mathrm{kPa}$;

$\log K=4.33-2144 /(50+273)+0.5 \log (7.9)=-1.859$

$\mathrm{K}=1.38 \times 10^{-2} \mathrm{mg}$ wt gain $/ \mathrm{hr}-\mathrm{cm}^{2}$

$\mathrm{H}_{2}$ Rate $=\left(120,000 \mathrm{~cm}^{2}\right)\left(1.38 \times 10^{-2} \mathrm{mg} / \mathrm{hr}^{-\mathrm{cm}^{2}}\right)\left(2.05 \times 10^{-3} \mathrm{~mol} \mathrm{H} / \mathrm{mg}\right.$ gain $)=$ $3.40 \mathrm{~mol} / \mathrm{hr}=1.9 \times 10^{-3} \mathrm{~g} / \mathrm{sec}$ 
If the 0.5 mol\% maximum impurity inventory allowed by [Irwin 1999a] were all conservatively taken as water and added directly to the $50 \mathrm{~mol} \%$ water vapor concentration used to obtain the above result, then the revised peak rate would be:

Revised Calculation of Peak Hydrogen Generation Rate@ $50{ }^{\circ} \mathrm{C}$

$$
\begin{aligned}
& \mathrm{P}_{\mathrm{S}}=(0.5+\mathbf{0 . 0 0 5}) \times 15.8 \mathrm{kPa}=7.98 \mathrm{kPa}=8.0 \mathrm{kPa} \\
& \mathrm{Log} \mathrm{K}=4.33-2144 /(50+273)+0.5 \mathrm{Log}(\mathbf{8 . 0})=-1.856 \\
& \mathrm{~K}=1.39 \times 10^{-2} \mathrm{mg} \text { wt gain } / \mathrm{hr}-\mathrm{cm}^{2} \\
& \mathrm{H}_{2} \text { Rate }=\left(120,000 \mathrm{~cm}^{2}\right)\left(1.39 \times 10^{-2} \mathrm{mg} / \mathrm{hr}-\mathrm{cm}^{2}\right)\left(2.05 \times 10^{-3} \mathrm{~mol} \mathrm{H}_{2} / \mathrm{mg} \mathrm{gain}\right)= \\
& \quad 3.42 \mathrm{~mol} / \mathrm{hr}=1.90 \times 10^{-3} \mathrm{~g} / \mathrm{sec}, \text { where the changes are shown in bold. }
\end{aligned}
$$

From the above result, it is apparent that the water ingress case of Table 3-2 would have absolutely no impact on the bounding peak hydrogen generation rate that [Pajunen 1998] reports for normal MCO drying operations at the CVDF.

7.3.2.2 Impact on Bounding Peak Rate for Off-Normal Operations. The $2.4 \times 10^{-3} \mathrm{~g} / \mathrm{sec}$ peak generation rate reported in section 5.2.7 of [Pajunen 1998] for a bounding surface area MCO under bounding off-normal conditions is based on saturation of the MCO atmosphere with water vapor. In view of the fact that the calculation is already based on water-saturated helium, any water vapor that is introduced by the helium itself can have no impact on the results.

\subsubsection{Evaluation of Worst Case Impurities Other Than Water or Air}

In addition to the oxygen, nitrogen or water vapor concentrations listed under the air ingress and water vapor ingress headings, Table 3-2 also incorporates the maximum impurity levels listed by Table 3-1 as the evaluated impurity basis for vendor supplied helium. These include: methane, at $2 \mathrm{ppm}$ (plus $8 \mathrm{ppm}$ from plant); neon, at $300 \mathrm{ppm}$; hydrogen, at $10 \mathrm{ppm}$; and carbon dioxide, at $10 \mathrm{ppm}$ (note that Table 3-2 lists $\mathrm{CO}_{2}$ at $11 \mathrm{ppm}$ for the air ingress case to account for $\mathrm{CO}_{2}$ from the atmosphere).

As already discussed in section 7.2.3, section 7.1 concludes that the worst case gas composition $(99.5 \mathrm{~mol} \% \mathrm{He}$ ) allowed for delivery to an MCO (Irwin 1999a) would not significantly degrade the thermal conductivity of the helium, even if the other $0.5 \mathrm{~mol} \%$ were assumed to be argon, which is the worst case gas for thermal conductivity. It follows that fuel temperatures will not be significantly higher as a result of any thermal conductivity loss that might be associated with the above listed impurities. Therefore, no impact on operating temperatures (higher temperatures would increase hydrogen generation rates) is expected to accrue from the neon.

As discussed in section 7.2.3, above, carbon dioxide and nitrogen are known to react with uranium, however hydrogen is not produced in those reactions.

Hydrogen may be radiolytically generated from methane or other hydrocarbon impurities within the supply gas, however radiolysis is a very slow process. Therefore, no increased hydrogen generation rates are expected to result from hydrocarbon impurities. 


\subsection{IMPACT ON REACTION HEAT GENERATION RATES}

Based on the following discussions and tabulated results, the worst case supply gas allowed by [Irwin 1999a] would have no measurable impact on the thermal power of any MCO.

Various SNF Project analyses that involve the thermal behavior of MCOs are based on the Hanford Spent Nuclear Fuel Safety Analysis Model, which is generally referred to as HANSF. Section 3.3 of the HANSF 1.3 User's Manual (Plys 1999) lists the following reactions and corresponding heats of reaction for oxidation of uranium.

When [free] oxygen is present [with or without liquid water or water vapor]:

$$
\mathrm{U}+\mathrm{O}_{2}=\mathrm{UO}_{2}+3.4 \times 10^{7} \mathrm{~J} / \mathrm{kg} \text { of oxygen. }
$$

When [free] oxygen is not present [the water may either be present as a liquid or vapor, or both]:

$$
\mathrm{U}+2 \mathrm{H}_{2} \mathrm{O}=\mathrm{UO}_{2}+2 \mathrm{H}_{2}+1.67 \times 10^{7} \mathrm{~J} / \mathrm{kg} \text { of oxygen [i.e., per kg of "weight gain"]. }
$$

\subsubsection{Evaluation of Impurities Listed for the Air Ingress Case of Table 3-2}

The above listed heats of reaction appear (at face value) to indicate that the air ingress case would increase reaction heat generation rates within the $\mathrm{MCO}$ because the listed heat of reaction per $\mathrm{kg}$ of weight gain is two times larger when free oxygen is present than it is when free oxygen is not present. However, the actual impact of the air ingress case would be to lower reaction heat generation rates within the $\mathrm{MCO}$ because the air ingress case would lower reaction rates by more than the above factor-of-two difference between the heats of reaction.

As discussed in section 7.2.1, above, Figures 4-2 and 5-2 of the Uranium Oxidation Rate Summary for the Spent Nuclear Fuel Project (Pajunen 1999), indicate that the air ingress case of Table 3-2 would reduce the overall uranium corrosion rate by more than the above factor of two difference between the heats of reaction. Therefore, the water ingress case will control.

\subsubsection{Evaluation of Impurities Listed for the Water Ingress Case of Table 3-2}

In order to assess impacts from any increased reaction heat generation rates that would result if the helium supply were to contain $0.5 \mathrm{~mol} \%$ water vapor, as it would for the water ingress case of Table 3-2, it is necessary to identify those processes and/or points in those processes where: 1) that water vapor has any potential to increase reaction rates; 2) where the increased reaction rates might affect the thermal stability of the $\mathrm{MCO}$ during a given process step; and/or 3) where the increased reaction rates might affect the end temperature of a given process step.

With respect to item 1 above, the same CVD process steps that were eliminated by section 7.2.2.1 from any further evaluation for impacts on particulate generation can also be eliminated from further evaluation for impacts on heat generation rate. 
Those CVD process steps that may be eliminated from further evaluation include:

a) The positive gage pressure purge (the "PWC/SCHe Purge") that occurs immediately after MCO draining, at which point any water vapor introduced into the MCO by the helium will be of no consequence because the MCO's contents will be covered and/or saturated with water; and

b) A series of totally evacuated steps (one $19 \mathrm{hr}$ duration "proof-of-dryness test" and two $1 \mathrm{hr}$ duration "pressure rebound tests," that immediately precede and follow the "proof test"), during which there can be no impact from impurities within the helium supply because the MCO contains essentially no helium under these conditions.

During all of the remaining CVD process steps, water vapor within the supply gas could result in increased reaction rates and, therefore, increased reaction heat generation rates. Based on the incremental heat generation calculations summarized in Table 7-6, section 7.4.2.1, evaluates possible impacts on the thermal stability of CVD process steps (item 2 above), while section 7.4.2.2 addresses possible impacts on their end temperatures (item 3 above). With the exception of the last two columns, which list joules of reaction heat instead of grams of generated particulate, Table 7-6 is identical to Table 7-5. A sample calculation follows Table 7-6.

Table 7-6. Calculation of Incremental Reaction Heat from Table 3-2 Water Case

\begin{tabular}{|c|c|c|c|c|c|c|c|c|}
\hline $\begin{array}{c}\text { MCO OPERATION } \\
\text { and } \\
\text { CVDF STEP NO. } \\
\text { (See Notes 1 \& 2) }\end{array}$ & $\begin{array}{l}\text { DURATION } \\
\text { (hr) }\end{array}$ & $\begin{array}{l}P_{M C o} \\
(k P a)\end{array}$ & $\begin{array}{l}P_{\text {Base }} \\
(\mathrm{kPa})\end{array}$ & $\underset{\text { (mole frac) }}{\mathrm{C}_{\mathrm{H} 2 \mathrm{O}}}$ & $\begin{array}{l}P_{\text {Add }} \\
(\mathrm{kPa})\end{array}$ & $\begin{array}{l}\mathrm{P}_{\mathrm{Rev}} \\
(\mathrm{kPa})\end{array}$ & $\begin{array}{c}\mathrm{H}_{\text {Baseline }} \\
\text { (joules) }\end{array}$ & $\begin{array}{c}\mathrm{H}_{\text {Revised }} \\
\text { (joules) }\end{array}$ \\
\hline $\begin{array}{l}\text { Ist Vac Dry Cycle } \\
\text { (27) }\end{array}$ & $\begin{array}{l}1.0 \\
1.0 \\
1.0 \\
1.0 \\
1.0 \\
1.0 \\
2.0 \\
\end{array}$ & $\begin{array}{r}17 \\
13 \\
10 \\
8 \\
8 \\
7 \\
7 \\
\end{array}$ & $\begin{array}{r}10.2 \\
6.0 \\
4.2 \\
2.6 \\
1.9 \\
1.5 \\
0.8 \\
\end{array}$ & $\begin{array}{l}0.005 \\
0.005 \\
0.005 \\
0.005 \\
0.005 \\
0.005 \\
0.005 \\
\end{array}$ & $\begin{array}{l}0.085 \\
0.065 \\
0.050 \\
0.040 \\
0.040 \\
0.035 \\
0.035 \\
\end{array}$ & $\begin{array}{r}10.285 \\
6.065 \\
4.250 \\
2.640 \\
1.940 \\
1.535 \\
0.835 \\
\end{array}$ & $\begin{array}{l}315 \\
220 \\
184 \\
158 \\
172 \\
152 \\
249 \\
\end{array}$ & $\begin{array}{l}316 \\
221 \\
185 \\
159 \\
174 \\
154 \\
254 \\
\end{array}$ \\
\hline 1st Thermal Reset (31) & 4.0 & $\begin{array}{c}129 \\
\text { (4 psig) }\end{array}$ & 10.0 & 0.005 & 0.645 & 10.645 & $180 \overline{5}$ & 1862 \\
\hline $\begin{array}{l}\text { 2nd Vac Dry Cycle } \\
\text { (33) }\end{array}$ & $\begin{array}{l}3.0 \\
1.0\end{array}$ & $\begin{array}{l}6 \\
6\end{array}$ & $\begin{array}{l}0.7 \\
0.3\end{array}$ & $\begin{array}{l}0.005 \\
0.005\end{array}$ & $\begin{array}{l}0.030 \\
0.030\end{array}$ & $\begin{array}{l}0.730 \\
0.330\end{array}$ & $\begin{array}{l}392 \\
87\end{array}$ & $\begin{array}{c}400 \\
91\end{array}$ \\
\hline $\begin{array}{l}\text { 2nd Thermal Reset } \\
\text { (37) }\end{array}$ & 4.0 & 129 & 8.0 & 0.005 & 0.645 & 8.645 & 1766 & 1836 \\
\hline $\begin{array}{c}\text { Cool Down and } \\
\text { Close Ports }(43-44)\end{array}$ & $\begin{array}{l}1.2 \\
1.0 \\
1.0\end{array}$ & $\begin{array}{l}129 \\
129 \\
129\end{array}$ & $\begin{array}{l}0.8 \\
1.2 \\
1.7\end{array}$ & $\begin{array}{c}0.005 \\
0.005 \\
-0- \\
\text { (see note 1) }\end{array}$ & $\begin{array}{c}0.645 \\
0.645 \\
-0- \\
\text { (see note 1) }\end{array}$ & $\begin{array}{c}1.445 \\
1.845 \\
1.7 \\
\text { (see note 1) }\end{array}$ & $\begin{array}{c}228 \\
125 \\
75\end{array}$ & $\begin{array}{c}306 \\
155 \\
75 \\
\text { (see note 1) } \\
\end{array}$ \\
\hline $\begin{array}{l}\text { TOTAL REACTION } \\
\text { HEAT (JOULES) } \\
\text { (Listed Steps Only) }\end{array}$ & \multicolumn{6}{|c|}{$\begin{array}{l}\text { Based on the above } 23.2 \text { hour }(83,520 \mathrm{sec}) \text { processing time, the } 6188 \mathrm{~J} \text { of } \\
\text { [revised] total reaction heat represent an average chemical reaction power } \\
\text { that is well under } 0.1 \mathrm{~W} \text {. The [revised] reaction power is seen to peak at } \\
0.13 \mathrm{~W} \text { during step } 31(1863 \mathrm{~J} / 4 \mathrm{hr} \times 3600 \mathrm{~s} \text { per } \mathrm{hr}=0.129 \mathrm{~J} / \mathrm{s}=0.13 \mathrm{~W}) \text {. }\end{array}$} & 5928 & 6188 \\
\hline \multicolumn{7}{|c|}{ TOTAL INCREMENTAL HEAT GENERATED BY MOISTURE IN HELIUM SUPPLY } & \multicolumn{2}{|c|}{$6188 \mathrm{~J}-5928 \mathrm{~J}=260 \mathrm{~J}$} \\
\hline
\end{tabular}




\section{Sample Calculation for Heat Generated During First Hour of 1st Vac Dry Cycle}

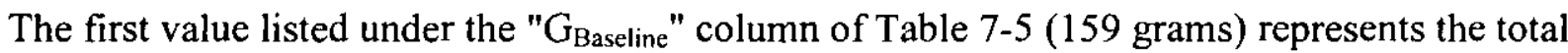
quantity of $\mathrm{UO}_{2}$ that would be generated within a safety basis surface area MCO during the first hour of the first "vacuum-with-He-purge" cycle (i.e., the "1st Vac Dry Cycle"), given a $10.2 \mathrm{kPa}$ partial pressure for water vapor within the $\mathrm{MCO}$. Based on the $159 \mathrm{~g}$ quantity of generated $\mathrm{UO}_{2}$ that [Sherrell 1998] calculates over that hour, the weight of oxygen taken on by the corroded uranium (i.e., the "weight gain" parameter for the heat of reaction equation given in section 7.4, above) would be:

$159 \mathrm{~g}$ of $\mathrm{UO}_{2} / 270 \mathrm{~g}$ of $\mathrm{UO}_{2}$ per mole $=0.589$ moles of $\mathrm{UO}_{2}$ or 0.589 moles of $\mathrm{O}_{2}$;

which, at $32 \mathrm{~g}$ of $\mathrm{O}_{2}$ per mole $=0.589$ moles $\times 32 \mathrm{~g} /$ mole $=18.85 \mathrm{~g}$ weight gain.

The same relationship (from section 7.2.2.1.2, above) that was used to calculate the values listed in Table 7-5 for the revised quantity of generated particulate can also be used for this calculation:

$G_{\text {Rev }}=\left(G_{\text {Base }}\right) \times\left(P_{\text {Rev }} / P_{\text {Base }}\right)^{1 / 2}$, where, in this case,

$\mathrm{G}_{\mathrm{Rev}}$ is the revised weight gain estimate (as grams of reacted $\mathrm{O}_{2}$ ),

$\mathrm{G}_{\mathrm{Base}}$ is the original weight gain estimate from [Sherrell 1998] (and as obtained above),

$\mathrm{P}_{\mathrm{Rev}}$ is the revised partial pressure of water vapor $(\mathrm{kPa})$, and

$\mathrm{P}_{\text {Base }}$ is the original partial pressure of water vapor used by [Sherrell 1998] .

For the first hour of the first vacuum drying cycle:

$$
\begin{aligned}
G_{\text {Base }}= & 18.85 \mathrm{~g}=18.85 \times 10^{-3} \mathrm{~kg} ; \\
P_{\text {Rev }}= & 10.285 \mathrm{kPa} \text {, from Table 7-5; and } \\
P_{\text {Base }}= & 10.20 \mathrm{kPa} \text { from Table 7-5; therefore } \\
G_{\text {Rev }}= & \left(18.85 \times 10^{-3} \mathrm{~kg}\right)(10.285 \mathrm{kPa} / 10.20 \mathrm{kPa})^{1 / 2}=\left(18.85 \times 10^{-3} \mathrm{~kg}\right)(1.0083)^{1 / 2}= \\
& \left(18.85 \times 10^{-3} \mathrm{~kg}\right)(1.0042)=18.93 \times 10^{-3} \mathrm{~kg}
\end{aligned}
$$

Finally, from section 7.4, above (when free oxygen is not present):

$$
\begin{aligned}
& \mathrm{U}+2 \mathrm{H}_{2} \mathrm{O}=\mathrm{UO}_{2}+2 \mathrm{H}_{2}+1.67 \times 10^{7} \mathrm{~J} / \mathrm{kg} \text { of weight gain; therefore } \\
& \mathrm{H}_{\text {Base }}=18.85 \times 10^{-3} \mathrm{~kg} \times 1.67 \times 10^{7} \mathrm{~J} / \mathrm{kg} \text { of weight gain }=315 \mathrm{~J} \text { during } 1 \mathrm{st} \text { hour; and } \\
& \mathrm{H}_{\text {Rev }}=18.93 \times 10^{-3} \mathrm{~kg} \times 1.67 \times 10^{7} \mathrm{~J} / \mathrm{kg} \text { of weight gain }=316 \mathrm{~J} \text { during } 1 \mathrm{st} \text { hour. } \\
& 29 \mathrm{of} 47
\end{aligned}
$$


7.4.2.1 Impacts on Thermal Stability. Based on the results summarized in Table 7-6, the worst case supply gas composition for incremental reaction heat (i.e., the water ingress case of Table 3-2) would have no impact on the thermal stability of a worst case (i.e., safety basis) MCO during any CVD operation, nor during any subsequent transportation or storage operation.

The potential for moisture within the helium supply to degrade the thermal stability of MCOs is greatest during the vacuum drying steps because those steps combine vacuum conditions, where convective heat transfer is greatly limited (depending on the vacuum quality), with a continuous helium purge, where any moisture within the helium represents additional reaction heat. However, from inspection of the values listed in the last two columns in Table 7-6 for the two vacuum drying cycles, it can be seen that neither the baseline reaction heat generation rate, nor the revised heat generation rate (after taking the moisture into account), would have any measurable impact on the thermal stability of any MCO under those conditions.

As a case in point, the highest heat generation rate during any vacuum drying step is seen to occur during the 1 st hour of the 1 st vacuum drying cycle, where the baseline generation rate is $315 \mathrm{joules} / \mathrm{hr}$, or $315 \mathrm{joules} / 3600 \mathrm{~seconds}$, or $0.0875 \mathrm{joules} / \mathrm{second}$, or $0.09 \mathrm{~W}$. The revised heat generation rate, after taking the $0.5 \mathrm{~mol} \%$ moisture content of the worst case supply gas into account, is seen to be 316 joules $/ \mathrm{hr}$, or 0.0878 joules/second, or $0.09 \mathrm{~W}$. In other words, there would be no measurable change to a baseline heat generation rate $(<0.1 \mathrm{~W})$ that would, itself, be lost in the background heat from a $400 \mathrm{~W}$ nominal decay power MCO. Even if the additional joule were assumed to appear all at once during a single second of the first hour, that outburst would only amount to $1 \mathrm{~W}$ out of $400 \mathrm{~W}$, or one fourth of one percent of the total thermal power.

It should be noted, that the above reaction heats already represent peak values because the "average" values listed by Table 7-6 conservatively represent the maximum rate (as opposed to the average rate) for a given interval, taken over the total time of that interval.

7.4.2.2 Impacts on End Temperature. Based on the small value ( $260 \mathrm{~J})$ shown at the bottom of Table 7-6 for the total amount of incremental heat that would accrue during the entire CVD process, no measurable impacts on $\mathrm{MCO}$ end temperatures would result from a worst case gas supply containing $0.5 \mathrm{~mol} \%$ water vapor. And, even if the worst case revised heat generation rate (as opposed to the average heat generation rate, or the even smaller incremental rate) were assumed to apply to the entire CVD operation, it would still represent a tiny fraction of the total heat output of a nominal power MCO. That worst case revised rate (1862 J in $4 \mathrm{hr}$, or $0.13 \mathrm{~W}$ ), which occurs during the first thermal reset operation, represents less than one tenth of one percent of a nominal decay power MCO's heat output: $0.13 \mathrm{~W} / 400 \mathrm{~W}=0.000325=0.033 \%$.

\subsubsection{Evaluation of Worst Case Impurities Other Than Water or Air \{NEW SECTION\}}

In addition to the oxygen, nitrogen or water vapor concentrations listed under the air ingress and water vapor ingress headings, Table 3-2 also incorporates the maximum impurity levels listed by Table 3-1 as the evaluated impurity basis for vendor supplied helium. These include: methane, at $2 \mathrm{ppm}$ (plus $8 \mathrm{ppm}$ from plant); neon, at $300 \mathrm{ppm}$; hydrogen, at $10 \mathrm{ppm}$; and carbon dioxide, at $10 \mathrm{ppm}$ (note that Table 3-2 lists $\mathrm{CO}_{2}$ at $11 \mathrm{ppm}$ for the air ingress case to account for $\mathrm{CO}_{2}$ from the atmosphere). 
As already discussed in section 7.3.3, above, no impact on operating temperatures is expected to accrue from the neon (higher temperatures could increase reaction rates and, therefore, heat generation rates). And, as discussed in section 7.2.3, above, carbon dioxide and nitrogen are known to react with uranium, however the reaction rates are very slow. Consequently, no measurable increase in heat generation rates would result from the carbon dioxide and nitrogen.

No impact on heat generation rates is expected to accrue from hydrogen. While hydrogen is known to react with uranium to form uranium hydrides, that reaction is endothermic. In any case, the maximum concentration of hydrogen within the supply gas (10 ppm) is seen to be insignificant when compared to the concentration levels that are expected to prevail (given that $1 \mathrm{vol} \%$ is equivalent to $10,000 \mathrm{ppm})$.

Finally, the $10 \mathrm{ppm}$ of hydrocarbon (taken here as methane) will not impact heat generation rates, nor would a significantly larger amount. This conclusion is supported by the following discussions and calculations.

As with hydrogen, the only exothermic reactions that methane can undergo within an MCO require the presence of oxygen in the gaseous state, i.e., they are combustion reactions. Based on the fact that methane has a higher "heat of combustion" than hydrogen, any addition of methane to an MCO would at first appear to increase its heat generating potential. However, this is actually not the case because the oxygen inventory will be limited. During normal operations, oxygen is produced by radiolysis, which is a slow process. Furthermore, because it is continually removed by reaction with exposed uranium surfaces (Duncan and Plys 1998), the oxygen concentration will never exceed 4 vol\% (see section 7.7 .2 .2 , above). Finally, a $0.1 \mathrm{~cm}^{2}$ air limiting leakage path has been established as the bounding case for evaluation of air ingress during MCO drying operations (see the second to last paragraph on page 2-2 of [Plys 1998]).

Given the above situation, where any combustion reaction that might occur within an MCO would be oxygen limited, a comparison can be made between hydrogen (which will always dominate the combustible gas inventory) and methane, based on the heat output per mole of oxygen consumed by the reaction (as opposed to the amount of methane or hydrogen consumed). Heats of formation are taken from pages 1606, 1599, and 1653 of [Lang's].

For reaction with hydrogen:

$2 \mathrm{H}_{2}+\mathrm{O}_{2}=2 \mathrm{H}_{2} \mathrm{O}(\mathrm{v})+2(57.8 \mathrm{Kcal})$, or $115.6 \mathrm{Kcal}$ evolved per mol O 2 reacted.

For reaction with methane:

$\mathrm{CH}_{4}\{@-17.9 \mathrm{Kcal} / \mathrm{mol}\}+2 \mathrm{O}_{2}=\mathrm{CO}_{2}\{@-94.05 \mathrm{Kcal} / \mathrm{mol}\}+2 \mathrm{H}_{2} \mathrm{O}(\mathrm{v})\{@-57.8 \mathrm{Kcal} / \mathrm{mol}\} ;$ $\Delta \mathrm{H}_{\mathrm{r}}=-94.05 \mathrm{Kcal} / \mathrm{mol} \mathrm{CO}+2\left(-57.8 \mathrm{Kcal} / \mathrm{mol} \mathrm{H}_{2} \mathrm{O}\right)-\left(-17.9 \mathrm{Kcal} / \mathrm{mol} \mathrm{CH}_{4}\right)=$

$-191.75 \mathrm{Kcal}$ for every two moles of oxygen reacted, therefore

$1 / 2 \mathrm{CH}_{4}+\mathrm{O}_{2}=1 / 2 \mathrm{CO}_{2}+\mathrm{H}_{2} \mathrm{O}+1 / 2(191.75 \mathrm{Kcal})$, or $95.9 \mathrm{Kcal}$ evolved per mol $\mathrm{O}_{2}$ reacted. 
Based on the above result (that $115.6 \mathrm{Kcal}$ of heat would be released for each mole of oxygen that reacts with hydrogen, compared to only $95.9 \mathrm{Kcal}$ per mole of oxygen that reacts with methane), hydrocarbon impurities within the helium will have no impact on heat generation rates within MCOs, provided that the reaction is oxygen limited.

\subsection{IMPACT ON INITIAL POST-CVD HYDROGEN INVENTORY}

Based on the following discussions and calculations, the worst case supply gas composition for hydrogen generation (the water ingress case of Table 3-2) might result in generation of an additional $0.2 \mathrm{~mol}$ of $\mathrm{H}_{2}$. This additional hydrogen is insignificant, considering that it amounts to less than one third of one percent of the 65.5 moles used for the hydrogen release calculations.

Section 5.2.1 of [Sherrell 1999] establishes a functional requirement to limit hydrogen release from MCOs to rates that allow the hydrogen concentration to be maintained at $1.0 \mathrm{~mol} \%$ or less within air filled spaces around MCOs (e.g., shipping cask, CSB storage tube, etc.).

That document then goes on to calculate a worst case hydrogen leakage rate that is based on challenging the mechanical seal's $1 \times 10^{-5} \mathrm{std} . \mathrm{cc} / \mathrm{sec}$ leak test acceptance criterion (Smith 1998) with a worst case hydrogen inventory $(65.5 \mathrm{~mol})$ that is, itself, based on the immediate appearance of the maximum amount of hydrogen that MCO Internal Gas Composition and Pressure During Interim Storage (Duncan \& Plys 1998) predicts for an MCO after 40 years of storage. That hydrogen inventory is very conservative in view of the fact that only about one tenth of the maximum inventory is expected to be generated during the first several years of service. See sections 4.3 and 7.1.2.2 of [Sherrell 1999] for additional details regarding the hydrogen inventory basis.

A conservative (worst case) evaluation of impacts from the CVDF's $0.5 \%$ maximum total helium impurity limit on the initial post-CVD hydrogen inventory of an MCO can easily be obtained by assuming that all of the contamination is from pure water, and then taking all of the hydrogen associated with that water as hydrogen gas. From section 7.1.2.2 of [Sherrell 1999], the maximum fill quantity (helium + impurities) used for that document's hydrogen release calculations is $41.3 \mathrm{~mol}$. If all of the impurities $(0.5 \%)$ are taken as water, then the backfill gas impurities could contain the equivalent of $41.3 \mathrm{~mol}$ total $\times 0.005 \mathrm{~mol} \mathrm{H} \mathrm{H}_{2} \mathrm{O} / \mathrm{mol}$ total $=0.21 \mathrm{~mol}$

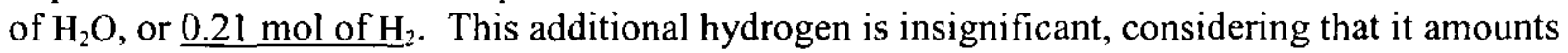
to less than one third of one percent of the 65.5 moles used for the hydrogen release calculations.

\subsection{IMPACT ON INITIAL POST CVD PROCESSING HELIUM INVENTORY}

Based on the considerations outlined below, the minimum initial backfill quantity calculation in section 7.1.2.1.1 of [Sherrell 1999] is being revised to include a 0.995 (mol He/mol total) correction factor to take the $0.5 \mathrm{~mol} \%$ maximum impurity limit of [Irwin 199a] into account. While the half percent shortfall would not have been significant enough to require revision of [Sherrell 1999], it is being addressed at this time because that document is currently undergoing revision to finalize the worst case (high) average fuel temperature to be used for the helium backfill calculation. 
Section 5.1.1.1 of the Multi-Canister Overpack Combustible Gas Management Leak Test Acceptance Criteria (Sherrell 1999) establishes the functional requirement to preclude air ingress to MCOs during shipment to, and storage at, the CSB by maintaining them at a positive gage pressure under all potential operating conditions. Section 5.1.1.1.2 of that document requires that the backfill gas used to maintain the positive gage pressure be completely inert. Gasses that might be consumed by reacting or otherwise interacting with uranium metal (e.g., hydrogen or nitrogen) are considered unacceptable because there is no way to be certain that they will be replaced by generation of additional hydrogen, or that any additional hydrogen that is generated will not be gettered by the uranium. Consequently, it is necessary to deduct any significant amount of non-inert impurities from the calculated initial helium backfill quantity. For the purposes of both this evaluation and the corresponding calculation in [Sherrell 1999] all of the impurities are considered non-inert, even though they will include small amounts of neon, argon, and other inert gases. Therefore, the minimum initial backfill quantity calculation in section 7.1.2.1.1 of [Sherrell 1999] includes a 0.995 (mol He/mol total) correction factor.

\subsection{IMPACT ON GAS COMPOSITION DURING INTERIM STORAGE}

Section 3.12 of MCO Internal Gas Composition and Pressure During Interim Storage (Duncan \& Plys 1998) lists the helium backfill gas purity as $99.9 \mathrm{~mol} \%$, whereas the goal of this document is to demonstrate that a worst case helium purity of $99.5 \mathrm{~mol} \%$ (Table $3-2$ ) is acceptable. Based on the following discussions, neither the air ingress case nor the water ingress case of Table 3-2 would impact the results and conclusions of [Duncan \& Plys 1998].

As a result of several competing chemical and radiochemical processes that will occur to one extent or another during the 40 year interim storage period, gas compositions within MCOs are expected to include varying amounts of both hydrogen and oxygen. Both oxygen and hydrogen can be removed (i.e., "gettered") by exposed uranium surfaces. While hydrogen gettering is expected to occur, no credit is taken for that process. Consequently, the gas depletion reaction of interest is oxygen gettering.

\subsubsection{Evaluation of Impurities Listed for the Water Ingress Case of Table 3-2}

The only impacts that would result from the water ingress case of Table 3-2 are: 1) a half percent reduction in the actual amount of helium introduced by the backfill procedure, which would also be associated with the air ingress case discussed in section 7.7.2; and 2) the inadvertent introduction of $0.2 \mathrm{~mol}$ of additional free water into the MCO with the backfill gas.

As stipulated in section 7.6 above, the helium inventory calculations of [Sherrell 1999b] take the half percent initial helium fill deficit into account. Note that one of the goals of the minimum backfill pressure requirement and subsequent helium loss calculations of [Sherrell 1999b] is to ensure that at least 30.3 moles of helium [per $500 \mathrm{~L}$ of void space] will remain within a worst [helium] case MCO after 40 years of storage. That $30.3 \mathrm{~mol}$ minimum goal is based on the $30.27 \mathrm{~mol}$ "nominal He backfill" that is used (with the exception of one "sensitivity case") to obtain the values reported in [Duncan \& Plys 1998]. Also note that the 30.27 mol helium inventory first appears explicitly in section 1.0 of Appendix D of [Duncan \& Plys 1998]. 
The 0.2 moles of additional hydrogen that could accrue from the additional 0.2 moles of free water have already been addressed by section 7.5 , which concludes that it would be insignificant.

\subsubsection{Evaluation of Impurities Listed for the Air Ingress Case of Table 3-2}

7.7.2.1 Impacts on Hydrogen Generation. Section 5.4 of [Duncan \& Plys 1998] addresses oxidation of exposed uranium surfaces by free water and the implications of that process for early hydrogen gas generation and depletion of free water, both of which are deemed acceptable, but undesirable outcomes. Just preceding the last paragraph of that section, [Duncan \& Plys 1998] states that "... the backfill gas of $99.9 \%$ He could contain by definition 1,000 ppm of air, or 200 ppm of $\mathrm{O}_{2}$, so initial $\mathrm{O}_{2}$ present as an impurity could easily render the question of net $\mathrm{H}_{2} \mathrm{O}$ oxidation moot." The overall implication is that the $200 \mathrm{ppm}$ initial oxygen concentration would be beneficial because it would provide additional assurance that "... sufficient residual free water is likely to remain in an MCO to prevent extensive thermal decomposition of $\mathrm{UO}_{3} \cdot 2 \mathrm{H}_{2} \mathrm{O}$." That section goes on to state that [even without any initial oxygen inventory in the backfill gas], "...depending on MCO power and the inventories of $\mathrm{Al}(\mathrm{OH})_{3}$ and $\mathrm{UO}_{3} .2 \mathrm{H}_{2} \mathrm{O}$, greater than 10 ppm oxygen will exist, and thereafter, net water vapor conversion to hydrogen will cease."

Based on the above, it is reasonable to assume that, from the standpoint of the its impact on uranium/water reactions, the $1000 \mathrm{ppm}$ initial oxygen concentration associated with a $0.5 \mathrm{~mol} \%$ air ingress would be considered desirable, though unnecessary.

7.7.2.2 Impact on Oxygen Concentrations. The worst case bounding oxygen MCO payload (which has no exposed uranium) evaluated by [Duncan \& Plys 1998] would also be the most sensitive to introduction of oxygen as an impurity within the backfill helium because that case takes no credit for removal of oxygen by the gettering process. Analytical results for that worst case payload are provided by Figure 5-3 of [Duncan \& Plys 1998] via plots depicting maximum oxygen concentration at 40 years versus initial $\mathrm{MCO}$ decay power for six different uranium surface areas that range from $1.5 \mathrm{~m}^{2}$ down to $0.00 \mathrm{~m}^{2}$. Although it is not specifically identified on Figure 5-3, the maximum possible decay power for the worst [oxygen] case MCO payload (zero reactive surface area) has been established at 528 Watts (Packer 1999). Therefore, the highest oxygen concentration currently shown for a bounding [oxygen] case MCO during forty years of storage corresponds to the point on Figure 5-3 of [Duncan \& Plys 1998] where the bold $" 0 \mathrm{~m}^{\wedge} 2 "$ line reaches 528 Watts. At that point the oxygen concentration is below $3.9 \mathrm{~mol} \%$, therefore the air ingress case of Table 3-2 would not impact the conclusion in section 2.0 of [Duncan \& Plys 1998], which states: "There is no combination of high MCO power, water content, and $0.0 \mathrm{~m}^{2}$ reaction area that leads to oxygen concentrations above $4 \%$ after 40 years, given nominal He backfill." 


\subsection{RESULTS}

\subsection{IMPACT ON THERMAL CONDUCTIVITY}

Based on section 7.1, the thermal conductivity of the worst case supply gas allowed by [Irwin 1999a] (see Table 3-2, below) would be within 1\% of the thermal conductivity listed for pure helium under all anticipated normal and off-normal MCO processing conditions. Considering the uncertainties inherent in a typical thermal analysis, it is reasonable to conclude that the small conductivity difference between pure helium and the worst case supply gas would have no impact on the validity of any thermal calculations that have been performed, or have yet to be performed, to support the SNF Project.

\subsection{IMPACT ON PARTICULATE GENERATION}

Based on section 7.2, no more than 169 grams of additional $\mathrm{UO}_{2}$ would be generated within a safety basis MCO as the result of the worst case supply gas allowed by [Irwin 1999a]. Considering the fact that a 169 gram increase represents only $5 \%$ of the 3255 gram contingency that is included in the 9765 gram grand total reported in Table 2-1 of [Sherrell 1998], it is not considered significant.

\subsection{IMPACT ON PEAK HYDROGEN GENERATION RATES}

Based on section 7.3, the worst case supply gas allowed by [Irwin 1999a] would have no impact on the peak hydrogen generation rates currently reported by [Pajunen 1998].

\subsection{IMPACT ON REACTION HEAT GENERATION RATES}

Based on section 7.4, the worst case supply gas allowed by [Irwin 1999a] would have no measurable impact on the thermal power of any MCO.

\subsection{IMPACT ON INITIAL POST-CVD PROCESSING HYDROGEN INVENTORY}

Based on section 7.5, the worst case supply gas allowed by [Irwin 1999a] might result in generation of an additional $0.2 \mathrm{~mol}$ of $\mathrm{H}_{2}$. This additional hydrogen is insignificant, considering that it amounts to less than one third of one percent of the 65.5 moles used for the hydrogen release calculations. 


\subsection{IMPACT ON INITIAL POST-CVD PROCESSING HELIUM INVENTORY}

The $0.5 \mathrm{~mol} \%$ helium shortfall identified in section 7.6 does not represent a significant impact, and would not, in and of itself, require revision of the minimum initial backfill quantity calculation in section 7.1.2.1.1 of [Sherrell 1999]. However, because that document is currently undergoing revision to finalize the worst case (high) average fuel temperature to be used in the helium backfill calculation, the backfill calculation is also being revised to include a 0.995 (mol $\mathrm{He} / \mathrm{mol}$ total) correction factor to take the $0.5 \mathrm{~mol} \%$ shortfall into account.

\subsection{IMPACT ON GAS COMPOSITION DURING INTERIM STORAGE}

Based on section 7.7, neither the air ingress case nor the water ingress case of Table 3-2 would impact the stated results and conclusions of MCO Internal Gas Composition and Pressure During Interim Storage (Duncan \& Plys 1998). 


\subsection{CONCLUSIONS}

\subsection{SNF PROJECT HELIUM GAS PROCUREMENT SPECIFICATION}

Table 9-1, which is reproduced in section 2.1 as Table 2-1, lists the recommended helium purity requirement $(\geq 99.96 \%$ ), along with the individual impurity limits for the SNF Project essential material specification for helium procurement.

Table 9-1. Recommended SNF Project Helium Gas Procurement Specification

\begin{tabular}{|l|c|}
\hline \multicolumn{2}{|c|}{ HELIUM GAS PROCUREMENT SPECIFICATION } \\
\hline $\mathrm{He}$ & Requirement (mole-to-mole basis) \\
\hline $\mathrm{H}_{2} \mathrm{O}$ & $\leq 99.96 \%$ \\
\hline Total $\mathrm{Hydrocarbon}\left(\right.$ as $\left._{\mathrm{CH}}\right)$ & $\leq 50 \mathrm{ppm}$ \\
\hline $\mathrm{O}_{2}+\mathrm{Ar}$ & $\leq 2 \mathrm{ppm}$ \\
\hline $\mathrm{N}_{2}$ & $\leq 30 \mathrm{ppm}$ \\
\hline $\mathrm{Ne}$ & $\leq 60 \mathrm{ppm}$ \\
\hline $\mathrm{H}_{2}$ & $\leq 300 \mathrm{ppm}$ \\
\hline $\mathrm{CO}_{2}$ & $\leq 10 \mathrm{ppm}$ \\
\hline
\end{tabular}

The essential material specification for helium procurement need be no more restrictive than the $99.9538 \mathrm{~mol} \%$ minimum helium concentration and associated maximum allowable individual impurity levels that are listed under the "Evaluated Impurity Basis" heading of Table 3-1. However, while the $\geq 99.9538 \%$ evaluated purity level would be acceptable, it would imply a level of precision that is not justified by the evaluation. On the other hand, it would not be appropriate to simply round the $99.9538 \%$ purity requirement down to $\geq 99.95 \%$ without identifying the missing $38 \mathrm{ppm}$ on the individual impurity listing as "other gases", and then justifying their acceptability. Consequently, the recommended overall purity specification $(\geq 99.96 \%)$ is more restrictive than the $\geq 99.9538 \%$ purity that was evaluated per Table $3-1$. None-the-less, it is still over a factor-of-ten less restrictive than a typical vendor's standard offering (see Appendix A).

Note that, for the purposes of this specification, a mole-to-mole basis is considered equivalent to a volume-to-volume basis. Also note that the $\geq 99.96 \%$ minimum purity requirement (i.e., 400 ppm maximum total impurities) would be violated if all of the listed impurities were to be present at their maximum individual limits (i.e., $462 \mathrm{ppm}$ total impurities). This is typical of most, if not all, commercial gas purity specifications. 
HNF-4702, Rev. 0

\subsection{HELIUM DELIVERED TO MCOS BY PLANT PIPING SYSTEMS}

For helium that is actually introduced into MCOs by the plant's gas distribution piping, the helium purity requirements and allowable impurity limits listed under the Air Ingress and Water Ingress columns of Table 3-2 should be combined as shown in Table 9-2, which is reproduced in section 2.2 as Table $2-2$.

Table 9-2. Recommended Specification for He Delivered to MCOs

\begin{tabular}{|l|c|}
\hline \multicolumn{2}{|c|}{ He DELIVERED to MCOs by PLANT PIPING SYSTEMS } \\
\hline \multicolumn{1}{|c|}{ Component } & Requirement \\
\hline $\mathrm{He}$ & $\geq 99.5 \%$ \\
\hline $\mathrm{H}_{2} \mathrm{O}$ & $\leq 4580 \mathrm{ppm}$ \\
\hline Total Hydrocarbon (as $\mathrm{CH}_{4}$ ) & $\leq 10 \mathrm{ppm}$ \\
\hline $\mathrm{O}_{2}+\mathrm{Ar}$ & $\leq 1020 \mathrm{ppm}$ \\
\hline $\mathrm{N}_{2}$ & $\leq 3600 \mathrm{ppm}$ \\
\hline $\mathrm{Ne}$ & $\leq 300 \mathrm{ppm}$ \\
\hline $\mathrm{H}_{2}$ & $\leq 10 \mathrm{ppm}$ \\
\hline $\mathrm{CO}_{2}$ & $\leq 11 \mathrm{ppm}$ \\
\hline
\end{tabular}

Note that any individual impurity may be present in concentrations at or below its listed limit, provided that the helium is maintained at least $99.5 \%$ pure, which is to say that the sum of the individual impurities actually present may not exceed $5000 \mathrm{ppm}$ within any gas sample, even though the sum of the individual limits listed by Table 9-2 totals almost twice that amount. Some other format would also be acceptable, provided that the resulting table allows any individual impurity to be present at concentrations up to the maximum concentration evaluated for that given impurity under either the air ingress case or the all water vapor ingress case of Table 3-2, while limiting the total impurity concentration to $0.5 \mathrm{~mol} \%$. 


\subsection{REFERENCES}

Coward, H. F., and G. W. Jones, 1952, Limits of Flammability of Gases and Vapors, Bureau of Mines Bulletin 503, Department of the Interior, United States Government Printing Office, Washington, D. C.

Duncan, D. R., and M. G. Plys, 1998, MCO Internal Gas Composition and Pressure During Interim Storage, HNF-SD-SNF-TI-040, Rev 3, DE\&S Hanford, Inc., Richland, WA

Edwards, W. S., 1998, Safety Analysis Report for Packaging (Onsite) Multicanister Overpack Cask, HNF-SD-TP-SARP-017, Rev 1, Waste Management Federal Services, Inc., Northwest Operations, Richland, WA

Irwin, J. J., 1999a, Cold Vacuum Drying Facility Design Requirements, HNF-SD-SNF-DRD-002, Rev 4, Numatec Hanford Corporation, Richland, WA.

Irwin, J. J., 1999b, Spent Nuclear Fuel Project Cold Vacuum Drying Facility Operations Manual, SNF-2356, Draft Rev 1A, Numatec Hanford Corporation, Richland, WA.

Lange, N. A., 1967, Lange's Handbook of Chemistry -- Revised Tenth Edition, McGraw-Hill Book Company, New York, NY.

McCracken, K. J.,1999, Cold Vacuum Drying Proof of Performance (First Article Testing) Test Results, HNF-4057, Rev 0, Flour Daniel Northwest, Richland, WA.

Pajunen, A. L., 1998, Design Basis Hydrogen Generation Rates in the Cold Vacuum Drying Facility, HNF-2458, Rev. 0A, COGEMA Engineering Corp., Richland, WA.

Pajunen, A. L., 1999, Uranium Oxidation Rate Summary for the Spent Nuclear Fuel Project, HNF-4165, Rev. 0, DE\&S Hanford Inc. Richland WA.

Pearce, R. J., 1989, A Review of the Rate of Reaction of Unirradiated Uranium in Gaseous Atmospheres, Central Electricity Generating Board, Berkeley Nuclear Laboratories, Berkeley, Glos.

Perry, R. H., 1973, and C. H. Chilton, Chemical Engineers' Handbook -- Fith Edition, McGraw Hill Book Company, New York, NY. 
Plys, M. G., 1998, FAI/98-33, Rev 3 Simulation of Normal and Off-Normal Multi-canister Overpack Behavior, HNF-2256, Rev. 2, DE\&S Hanford Inc., Richland WA.

Plys, M. G., et. al., 1999, HANSF 1.3 Users's Manual, SNF-3650, Rev. 1, DE\&S Hanford Inc., Richland WA.

Praga, A. N., 1998, MCO Loading and Cask Loadout Technical Manual, HNF-2169, Rev. 0, DE\&S Hanford Inc., Richland WA.

Reilly, M. A., 1998, Spent Nuclear Fuel Project Technical Databook, HNF-SD-SNF-TI-015, Rev. 6, DE\&S Hanford, Inc., Richland, WA.

Sherrell, D. L., 1998, Post Fuel-Cleaning Corrosion of Uranium Within MCO Payloads, HNF-3048, Rev 0, with ECN 648623, DE\&S Hanford Inc., Richland WA.

Sherrell, D. L., 1999a, Spent Nuclear Fuel Inventory in Bulk MCO Water at the Cold Vacuum Drying Facility, HNF-SD-W441-CN-001, Rev. 3, DE\&S Hanford Inc., Richland WA.

Sherrell, D. L., 1999b, Multi-Canister Overpack Combustible Gas Management Leak Test Acceptance Criteria, HNF- 2155, Draft Rev. 2, DE\&S Hanford Inc., Richland WA.

Smith, K. E., 1998, Performance Specification for the Spent Nuclear Fuel Multi-Canister Overpack, HNF-S-0426, Rev. 5, DE\&S Hanford Inc., Richland WA.

Yaws, C. L., 1977, Physical Properties, A Guide to the Physical, Thermodynamic and Transport Property Data of Industrially Important Chemical Compounds, McGraw-Hill Publishing Co., New York, New York. 
HNF-4702, Rev. 0

APPENDIX A: Vendor Supplied Composition Information (OXARC, Inc) 


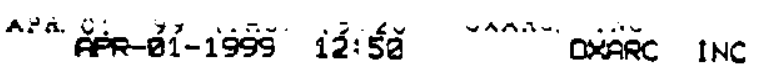

HNF-4702, Rev. $9, \ldots$.

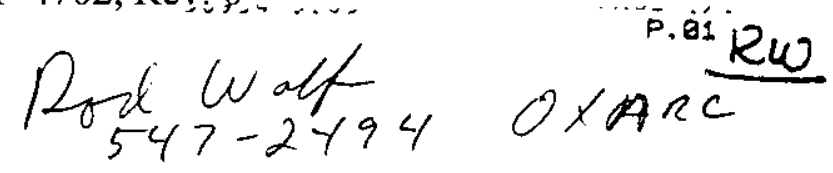

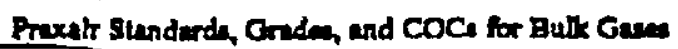

\begin{tabular}{|c|c|c|c|}
\hline \multicolumn{4}{|c|}{ 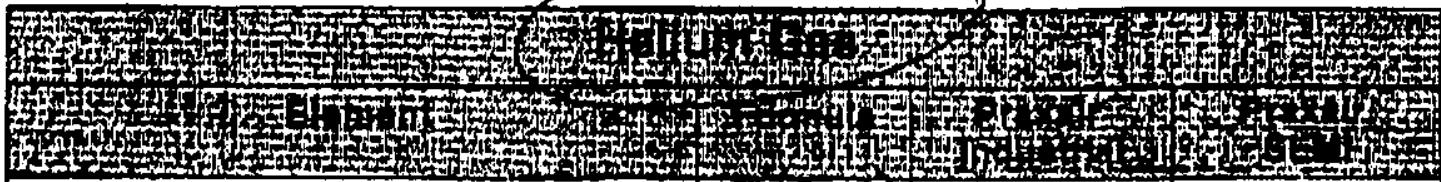 } \\
\hline Purty $(x) \quad(30$ PPM MaX TOT $(M)$ & (1), & 08.097 & 89.897 \\
\hline Molsture (ppm v/N) & $\mathrm{H}_{2} \mathrm{O}$ & $6.0-1$ & 3.0 \\
\hline Total Hydrocartono (as Malhano) & & 1.0 & 1.0 \\
\hline Oxvenen plus Argon & $O_{1}+A P$ & 47 & 3.0 \\
\hline Nlirogen & $\mathbf{N}_{\mathbf{2}}$ & 6.0 & 6.0 \\
\hline Noon & Ne & 30.0 & 23.0 \\
\hline Hydrogen & $\mathrm{H}_{3}$ & 1.0 & 1.0 \\
\hline Carbon Dloxldo & $\mathrm{CO}_{2}$ & 1.07 & 1.0 \\
\hline Product Codo & & 00751 & 00761 \\
\hline
\end{tabular}

\section{NOTEA:}

1. All unte in ppm (mola/mole) unlese Indicatod othenwise

2. Praxals Induetrial = Standard Otraring

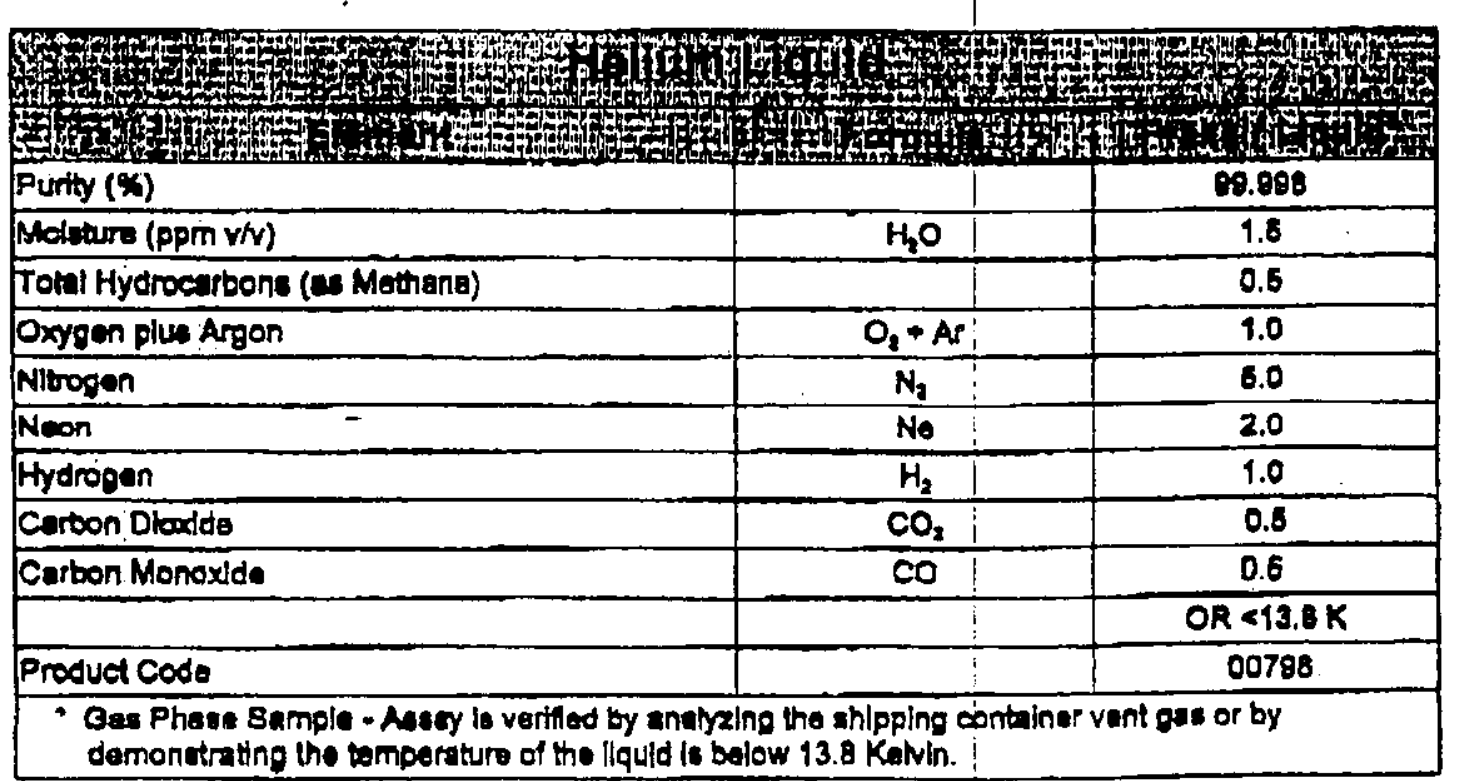

\section{Norfs:}

1. All unite In ppm (mole/molo) unices indicated othenwise

P-19-091

isrued: $11 / 96$

$$
\begin{aligned}
& 316-3252 \\
& \text { Walter }
\end{aligned}
$$

Pace $1-5$ of 3

TOTAL P.B1 
HNF-4702, Rev. 0

APPENDIX B: Independent Review 


\section{REVIEW PLAN}

NOTE: Reviews requiring OCRWM QARD Document Review compliance, or OCRWM QARD Peer Review compliance shall complete all applicable sections of this plan.

\section{PROJECT: SNF Project}

2. SUBJECT OF REVIEW: The document under review evaluates the impacts of impurities within helium introduced into multi-canister overpacks (MCO) s at the Cold Vacuum Drying Facility (CVDF).

\section{DOCUMENTS TO BE REVIEWED:}

\begin{tabular}{|l|c|c|}
\hline \multicolumn{1}{|c|}{ Document Title } & Document Number & Rev. No. \& Date \\
\hline $\begin{array}{l}\text { Spent Nuclear Fuel Inventory in Bulk MCO Water at the Cold } \\
\text { Vacuum Drying Facility }\end{array}$ & HNF-4702 Rev 0, Aug 1999 \\
\hline \hline
\end{tabular}

\section{SCOPE OF REVIEW: Check the appropriate review criteria boxes.}

NOTE: All asterisk ( $\left.{ }^{\star}\right)$ criteria items SHALL be considered for reviews reguiring OCRWM QARD DOCument Review compliance. All triangle (v) items SHALL be included, as appropriate, for reviews requiring OCRWM QARD Peer Review compliance.

[] Applicability*

[X] Correctness

[X] Technical adequacy*

[x] Completeness*

[x] Accuracy*

(] Compliance with established requirements*

[X] Documented and soundly based assumptions*

[i Alternate interpretations*

[1 Adequacy of requirements and criteria*

[X] Appropriateness and limitations of the methods and implementing documents used to complete the $\mathrm{n}$ work under review*

[] Adequacy of application*

[X] Accuracy of calculations*
(1) Documented and soundly based inferences and conclusions $\star \nabla$
[1 Uncertainty of results and impact if wrong*
[X] Consistent with and traceable to data
[x] Data traceable to its origin
[X] Documentation being reviewed internally consistent
[] Documentation being reviewed consistent with other documents listed for review
[] Correct application of software
[] List follow up reviews that may be needed
[] Software verification documents
[] Software validation documents
(] Adequacy of applicable codes and standards

5. PURPOSE OF REVIEW: (List objectives to be achieved by this review.) The OCRWM QARD DOCument Review covered by this plan is intended to confirm the overall conclusions regarding the acceptability of: 1) the document's 99.953 f evaluated purity basis (Table $3-1$ ) for helium deliverd to the cVDF from the vendor; and 2) the CVDF's current $99.5 \%$ purity requirement for helium that is actually introduced into MCO's (Table $3-2$ ).

Type of Roview: Based on evaluation of the subject document against the criteria listed in section 5.0 of AP 6-009-00, the document meets criteria (Sec 5.1.1.C and Sec 5.1.3) requiring an OCRWM QARD DOcument Review. Based on the criteria in Section 5.2 of the AP, the additional rigor of an OCRHM OARD Peer Review is not required.

6. REVIEWERS: Reviews requiring OCRWM QARD Document Review compliance shall attach a summary of each reviewer(s) experience. Add reviewer(s) technical qualifications and credentials that are recognized and verifiable to this summary for OCRWM OARD Peer Review compliance.

\begin{tabular}{|c|c|c|c|c|c|}
\hline & Reviewer Name & $\begin{array}{c}\text { Technical } \\
\text { Expertise }\end{array}$ & $\begin{array}{c}\text { Expected Level of } \\
\text { Effort }\end{array}$ & $\begin{array}{c}\text { Charge } \\
\text { Code }\end{array}$ & Special Instructions \\
\hline 1 & REVIEWER PD Rittmann & Safety Analysis & As Required & N/A & $\begin{array}{l}\text { Review document, perform } \\
\text { alternate calculations where } \\
\text { appropriate, and complete } \\
\text { Review Comment Record }\end{array}$ \\
\hline \hline
\end{tabular}

7. REVIEW REQUIREMENTS: Ligt all requirements applicable to the reviewer. NOTE: All reviews requiring OCRWM QARD Document or Peer Review compliance comments shall document comments on a RCR (A-6400-090.1). No special review requirements.

\begin{tabular}{|c|c|}
\hline $\begin{array}{l}\text { Sponsoring Manager Approval of Review Plan } \\
\text { ifign and datel } \mathrm{j} \text {. R. Frederickson }\end{array}$ & $\begin{array}{l}\text { Pesign tuthority concurrenge of Review Plan } \\
\frac{5 \mathrm{~m} \text { (sign and date) L. H. Goldmann }}{8 / 9 / 99}\end{array}$ \\
\hline
\end{tabular}

I haje rad fh review plan and confirm that my review addressed the scope/requirements listed in sections 6 \& 7 above.

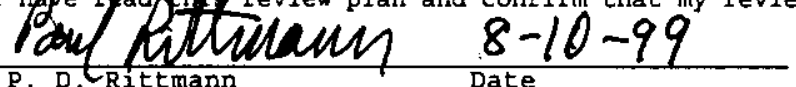

A-6002-370(07/97) GEF439 
HNF-4702, Rev. 0

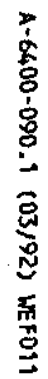

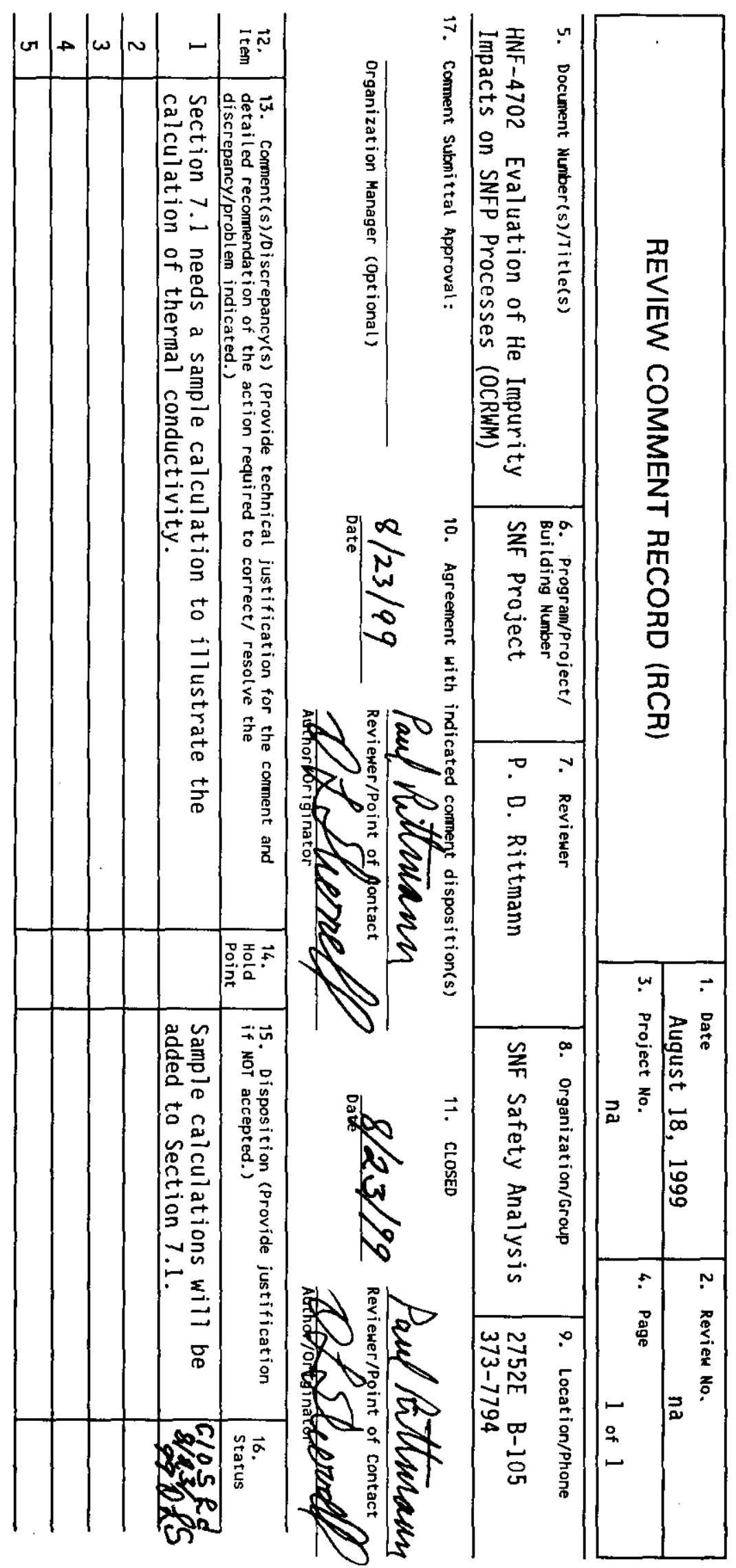


HNF-4702, Rev. 0

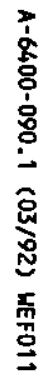

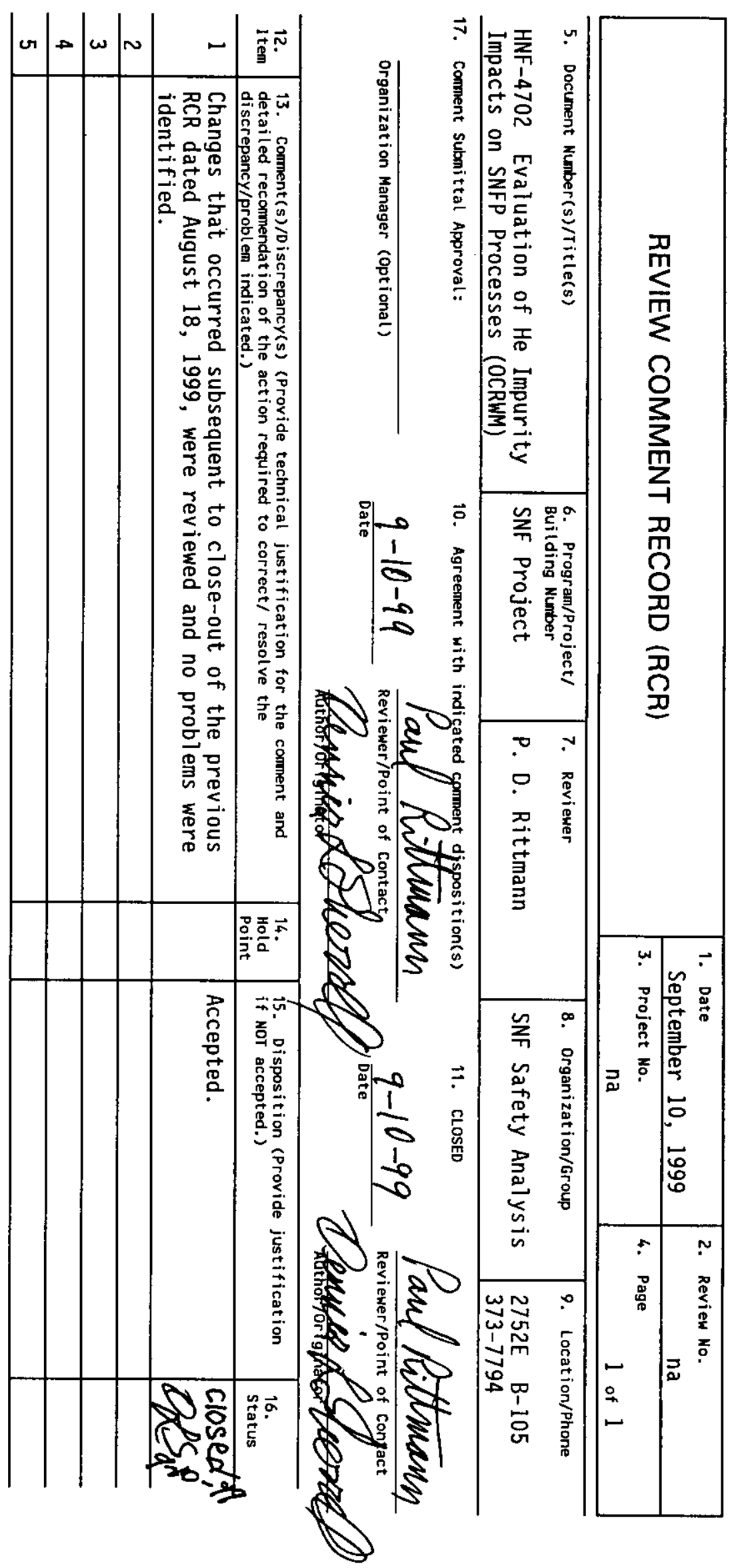




\section{PEER REVIEW CHECKLIST}

Document Reviewed: HNF-4702 Rev 0

Scope of Review: Whole thing

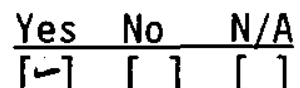

Previous reviews complete and cover analysis, up to scope of this review, with no gaps.

[U] [ ] [ ] Problem completely defined.

[ ] [ ] [J Accident scenarios developed in a clear and logical manner.

[y [ ] [ ] Necessary assumptions explicitly stated and supported.

[ ] [ ] [ J Computer codes and data files documented.

[u] [ ] [ ] Data used in calculations explicitly stated in document.

[J [ ] [ ] Data checked for consistency with original source information as applicable.

[ ] [ ] [4 Mathematical derivations checked including dimensiona] consistency of results.

[J [ ] [ ] Models appropriate and used within range of validity or use outside range of established validity justified.

[Y [ ] [ ] Hand calculations checked for errors. Spreadsheet results should be treated exactly the same as hand calculations.

[ ] [ ] [Y Software input correct and consistent with document reviewed.

[ ] [ ] [J Software output consistent with input and with results reported in document reviewed.

[J [ ] [ ] Limits/criteria/guidelines applied to analysis results are appropriate and referenced. Limits/criteria/guidelines checked against references.

[ 5 [ ] [ ] Safety margins consistent with good engineering practices.

[于 [ ] [ ] Conclusions consistent with analytical results and applicable limits.

[ $\mathcal{F}_{\text {[ }}$ ] [ ] Results and conclusions address all points required in the problem statement.

[ ] [ ] [Y Format consistent with appropriate NRC Regulatory Guide or other standards

[ ] [ $[\cdot]$ Review calculations, comments, and/or notes are attached.

[〕 [ ] Document approved.

Peer Reviewer: P. D. Rittmann, PhD CHP

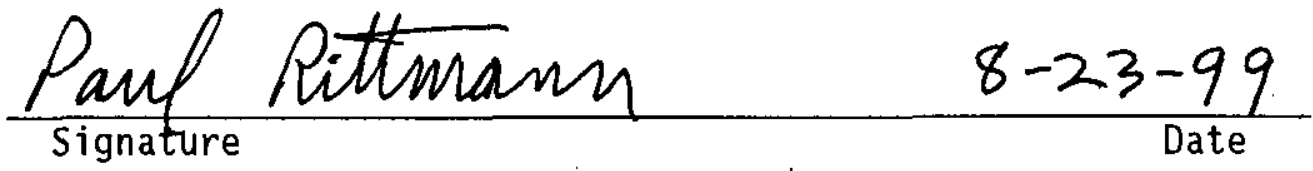




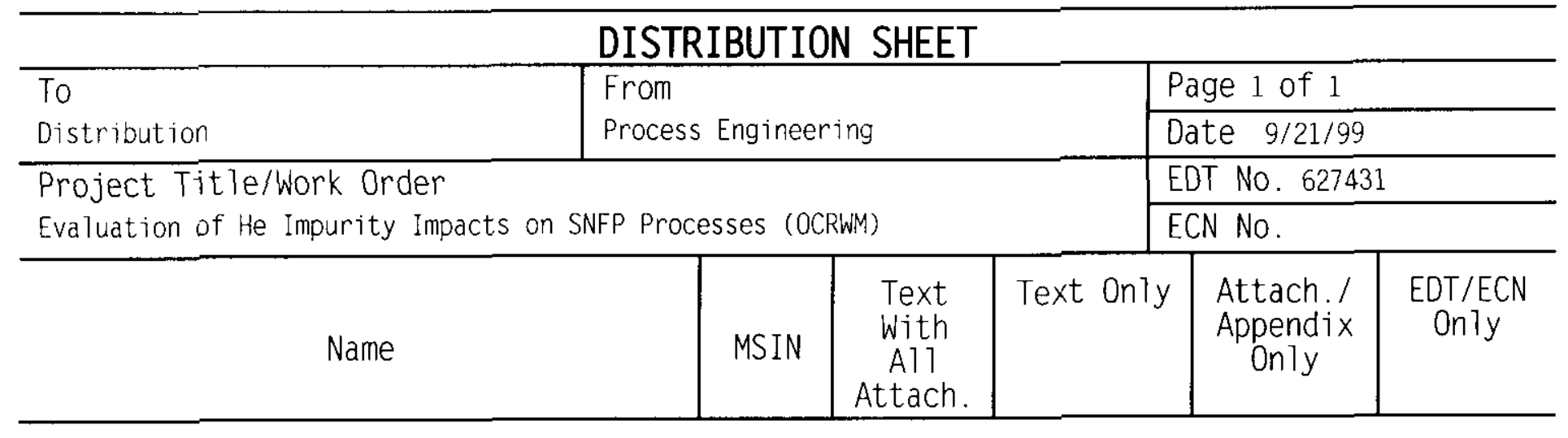

W. C. Alaconis

K. E. Ard

G. D. Bazinet

S. A. Brisbin

D. M. Chenault

D. L. Cooley

J. 0. Cloud

K. C. Conrad

R. D. Crowe

D. R. Duncan

R. D. Dunlap

J. R. Frederickson

R. G. Gant

R. L. Garrett.

L. J. Garvin

L. H. Goldmann

M. J. Gunderson

R. J. Guse

C. S. Haller

P. M. Hickey

J. J. Irwin

M. J. Klem

R. A. Larson

J. D. Mathews

K. J. McCracken

D. W. Medford

M. A. Medsker

C. R. Miska

M. J. Packer

A. L. Pajunen (10)

M. G. Piepho

C. C. Pitkoff

P. D. Rittman

R. P. Ruth

L. S. Semmens

D. L. Sherrel1 (10)

D. W. Smith

K. E. Smith

J. E. Turnbaugh

D. J. Watson

J. L. Weamer

R. H. Webb

$R$. Whitehurst

SNF Project Files
R3-86

$\times 3-85$

S8-06

R3-86

R3-86

$\times 3.85$

R3-86

$\times 3-80$

R3-26

R3-86

S1-51

R3-86

$\times 3-79$

R3-26

R3-26

R3-86

$\times 3-76$

R3-86

R3-11

$\times 3-73$

R3-86

R3-86

R3-86

$\times 3-65$

R3-86

R3-86

R3-26

R3-86

R3-86

R3-86

R3-26

R3-26

R3-26

R3-11

$\times 3-79$

R3-86

R3-11

R3-86

$\times 3-79$

$\times 3-79$

$\times 3-85$

R3-26

R3-86

R3-11 